\title{
1 Water in type I chondrules of Paris CM chondrite
}

2

\author{
A. Stephant ${ }^{1,2^{*}}$, L. Remusat $^{1}$ and F. Robert ${ }^{1}$
}

${ }^{1}$ Institut de Minéralogie, de Physique des Matériaux, et de Cosmochimie (IMPMC) Sorbonne Universités - Muséum National d'Histoire Naturelle, UPMC Univ Paris 06, UMR CNRS 7590, IRD UMR 206, 61 rue Buffon, F-75005 Paris, France.

${ }^{2}$ Center for Meteorite Studies, Arizona State University, Tempe, Arizona 85287-6004, USA

* Corresponding author: Alice Stephant: alice.stephant@gmail.com

\begin{abstract}
Hydrogen isotopic ratio and water concentration have been measured with the NanoSIMS in olivine, pyroxene and mesostasis phases in individual chondrules from the carbonaceous chondrites Paris (CM2), Renazzo (CR2) and ordinary chondrite Bishunpur (LL3). On average, chondrule pyroxenes in Renazzo, Bishunpur and Paris contain 893 \pm 637 ppm (1SD), 879 \pm 536 ppm and $791 \pm 227$ ppm $\mathrm{H}_{2} \mathrm{O}$. Chondrule olivines from Renazzo and Bishunpur vary from $156 \pm 44 \mathrm{ppm}$ to $222 \pm 123 \mathrm{ppm}$. Olivines in the Paris chondrules have high water concentration $\left(603 \pm 145\right.$ to $\left.1051 \pm 253 \mathrm{ppm}_{2} \mathrm{O}\right)$ with a minimum mean value of $645 \pm 99 \mathrm{ppm}$. $\delta \mathrm{D}$ ranges from $-212 \pm 125 \%$ o to $15 \pm 156 \%$ and from $-166 \pm 133 \%$ o to $137 \pm 176 \%$ o in Renazzo and Bishunpur chondrule olivines, pyroxenes and mesostases, respectively. In Paris chondrules, $\delta \mathrm{D}$ ranges from $-398 \pm 23 \%$ o to $366 \pm 35 \%$; this represents an extreme variation over $764 \%$. Paris olivines and pyroxenes are either enriched or depleted in deuterium relative to the mesostasis and no systematic isotopic pattern is observed. Simple model of chondrules hydration during parent body hydrothermal alteration is difficult to reconcile with such isotopic heterogeneity. It is proposed that a hydrous component, having a $\delta \mathrm{D}$ of c.a. $-400 \%$, in the chondrule precursors, has been outgassed at $800-900^{\circ} \mathrm{C}$ in the gas phase. Nevertheless, a residual water fraction remains trapped in Paris chondrules. Quantitative modeling supports this scenario.
\end{abstract}

\section{Introduction}

Some carbonaceous chondrites (CC) hold hydrated minerals and contain up to 10 wt. $\% \mathrm{H}_{2} \mathrm{O}$ (Kerridge, 1985). They are the most plausible source of water delivery to the Earth (Marty, 2012; Walsh et al., 2011) as they display, on average, a similar D/H ratio as the Earth oceans, i.e. $155.76 \times 10^{-6}$ (Robert, 2006). Thus, the carbonaceous chondrites are the key samples to constrain the origin of water on Earth. CM carbonaceous chondrites constitute an interesting class for studying aqueous alteration. Indeed, the CM chondrite group embraces type 1 (i.e. heavily aqueously altered) and type 2 (i.e. less aqueously altered) chondrites. Manganese-chromium dating of carbonates in $\mathrm{CM}$ chondrites gave a reliable aqueous alteration age of $4563.4+0.4 /-0.5$ million years (Fujiya et al., 2012); younger age than previous estimations (de Leuw et al., 2009). This CM carbonate age suggests the late onset of aqueous activities in the Solar System and allows Fujiya et al. (2012) to estimate that CM parent body accreted roughly 3.5 Myr after the birth of the Solar System. 
Hydrated minerals and organic matter carry hydrogen in aqueously altered chondrites. Aqueous alteration of silicate minerals in these chondrites is evidenced by the occurrence of hydrous phyllosilicates, as serpentines, saponites, and smectites, which are the predominant phase in matrices of CCs (Garenne et al., 2014; Beck et al., 2010), often associated with carbonates and oxides (Howard et al., 2011) The petrologic chondrite classification reflects varying degrees of aqueous alteration in different groups of chondritic meteorites (Van Schmus and Wood, 1967). Classification of CMs is established based on a sequence of aqueous alteration (Alexander et al., 2013; Browning et al., 1996; Rubin et al., 2007).

Whether alteration on $\mathrm{CM}$ chondrite took place in the protosolar nebula or on the parent body is still a matter of debate: Ciesla et al. (2003) have argued for the hydration of silicate dust in the icy regions of the nebula during the passage of shock waves and Bishoff (1998) favors pre-accretionary alteration in the nebula, based on the relationship between fine-grained rims and their surrounding components. On the other hand, several observations support the hypothesis that the aqueous alteration occurred after the accretion onto the parent body (Brearley, 2003). For example, the existence of alteration zones, as Fe-rich aureoles around metal grains (Hanowski and Brearley, 2001), fluid inclusions (Fieni et al., 1978; Zolensky et al., 1999), supports this hypothesis. The oxygen isotopic data also indicate a parent body alteration: Young et al. (1999) explained the oxygen isotopic diversity of CC by simple down-temperature fluid flow within the parent body, based on the systematic relationships between the bulk oxygen isotopic composition of CC and the degree of aqueous alteration.

62 Chondrites show a systematic enrichment in deuterium relative to the molecular hydrogen of the 63 protosolar nebula (Boato, 1954). The D/H ratio in matrix clays of chondrites has been assumed to reflect the $\mathrm{D} / \mathrm{H}$ ratio of water that has circulated during the aqueous alteration of the parent body. Based on petrographic and mineralogical analyses in the heavily aqueously-altered Alan Hills 81002 CM2 chondrite, Hanowski and Brearley (2001) argued for the alteration of chondrules in a parent body environment. Nevertheless, hydrogen isotopic measurements performed on the Bishunpur and Semarkona LL3 ordinary chondrites and Renazzo CR2 carbonaceous chondrite showed large D/H heterogeneities among matrix clays and also between silicate minerals in chondrules (Deloule and Robert, 1995; Deloule et al., 1998). An isotopic reequilibration during hydrothermal alteration on the parent body by a homogenous aqueous reservoir cannot explain alone the heterogeneities of $\mathrm{D} / \mathrm{H}$ ratio in these chondrites. D-enrichment of chondrite water could result from 2 scenarios (Bonal et al., 2013): (i) enrichment is an heritage of water formed in the outer solar system or presolar molecular clouds (Deloule and Robert, 1995; Deloule et al., 1998), variations observed in chondrites reflect different water reservoirs having different $\mathrm{D} / \mathrm{H}$ ratios ; (ii) light water was formed in the warmer inner solar system and got enriched by secondary processes during aqueous alteration on the parent body including exchange with D-rich organics, oxidation of metal or other processes able to fractionate the initial $\mathrm{D} / \mathrm{H}$ of water (Eiler and Kitchen, 2004; Alexander et al., 2012)

The CM2 Paris is a fresh sample that suffered only limited parent-body transformations, as revealed by preservation of amorphous silicates in the matrix. It is considered as the least altered CM chondrite currently known, classified as a CM2.7 (Hewins et al., 2014; Marrocchi et al., 2014). This sample offers a unique opportunity to study the initial stages of aqueous alteration on the CM parent body by investigating

83 well preserved type I chondrules, which are not prone to aqueous alteration and are the least altered 84 85 component in CM chondrites. Moreover, Paris exhibits heterogeneous alteration areas (Hewins et al., 2014), which bring us a large set of chondrules ranging from low to high alteration rate. Here we 
investigated the water content and the $\mathrm{D} / \mathrm{H}$ ratio in different phases (olivine, pyroxene and mesostasis) of 12 type I chondrules and the surrounding matrix from Paris. In comparison, 4 chondrules from Bishunpur (LL3) and 3 chondrules from Renazzo (CR2) were also analysed. Our aim was to determine if chondrules and matrix underwent the same aqueous alteration, by using the $\mathrm{D} / \mathrm{H}$ ratio, or if they were subjected to different hydration episodes. The high lateral resolution of NanoSIMS allows measuring water content and hydrogen isotopic ratio in contiguous olivine, pyroxene and mesostasis of chondrules.

\section{2. Samples}

\section{$93 \quad 2.1$. Objects of study}

The Paris chondrite is a breccia with varying degrees of alteration and thus it contains both well preserved and altered chondrules. Three sections were analyzed in three sessions: one mounted in epoxy (i.e. Session I- chondrules 4, 6, 9, 19, 24 and 27) and two epoxy-free (i.e. Session II: chondrules 1 and 7; Session III: chondrules A, B, D and E). The latest were chosen to assess vacuum issues on the hydrogen contamination in addition to the effect of epoxy -expected to impregnate the sample at a fine scale- that could bias our measurements (Aubaud et al., 2007; Hauri et al., 2006; Stephant et al., 2014). The three sections of Paris were used for D/H analyses but only the one of session III were used for water content measurements. Renazzo and Bishunpur, mounted in epoxy, were also analysed as they exhibit heterogeneities of the $\mathrm{D} / \mathrm{H}$ ratios in their chondrules, documented by previous studies (Deloule and Robert, 1995; Deloule et al., 1998) (i.e. Session IV - chondrules X, Y, Z and I, J, K, L). As such, they are used as references in this study. Renazzo is a CR2 chondrite which contains abundant type I chondrules (Weisberg et al., 1993) with intermediate level of alteration, evidenced by the replacement of chondrule mesostases by phyllosilicates. Bishunpur is a LL3.1 ordinary chondrite whose aqueous alteration was limited to the production of smectite in the matrix (Alexander et al., 1989). Type I chondrules were imaged using a JEOL JSM 840-A SEM installed at MNHN. Chemical characterization of olivine and

111 Paris contains markedly more type I than type II chondrules and their size ranges from $\sim 100$ to $\sim 500 \mu \mathrm{m}$. 112 In addition, type I chondrules in Paris have various petrologic characteristics. We selected 12 chondrules of different textural types and various degrees of aqueous alteration in order to survey the range of 114 chondrules present in Paris. Backscattered electron images of these 12 chondrules are presented in Figure 1151 to illustrate this diversity: barred olivines (chondrules 19, 24 and 1), radial pyroxene (chondrule 4), and porphyritic chondrules. Degree of chondrule aqueous alteration is established on the amount of metal globules, glassy stage of mesostasis and presence of alteration aureole. Moreover, various degrees of aqueous alteration are observed in chondrule mesostasis. For instance, chondrule 19 is a well-preserved object with glassy mesostasis and metal globules whereas chondrule 27 exhibits an altered mesostasis in its center and lacks of Fe-rich globules (Fig.1). X-ray elemental maps obtained by EDX allow us to select the target areas for NanoSIMS analysis; we aimed at areas with contiguous occurrences of olivine, pyroxene and mesostasis. The EMPA measurements (Table 1) indicate that all olivines type I chondrules from Paris are magnesium-rich $(\mathrm{Fa}<2)$. Low-Ca pyroxenes show limited compositional range (Fs ranges from 0.7 to 17.5; Wo ranges from 0.4 to 5.9 with an exception at 38.3). We also chose 4 representative type I chondrules in Bishunpur and 3 in Renazzo. 
127 Silicate standards were used for calibration of water contents and for instrumental mass fractionation on 128 D/H ratio. These standards match different phases analyzed in chondrules: pyroxene KBH1, olivine KLV129 23, glass DR15-1-5, glass DR20-1-1, amphibole Mont Emma and amphibole Kipawa (Clog, 2010; 130 Deloule, 1991; Koga et al., 2003). Their chemical compositions are reported in Table 2. Samples were 131 mounted in such a manner to reduce a contribution of epoxy to the $\mathrm{OH}$ signal while having a nice polished 132 surface: holes were drilled in a $10 \mathrm{~mm}$ aluminium disk with a $2 \mathrm{~mm}$ diameter drill bit. In each hole, 133 samples were mounted individually with epoxy and then polished down to $0.25 \mu \mathrm{m}$ diamond paste. 134 Mounts were carbon-coated, thickness $20 \mathrm{~nm}$. Chondrites and standards were outgassed for one week in 135 the NanoSIMS airlock before each analytical session.

\section{3. Methods}

137 3.1 Quantification of water content

138 Elemental measurements were performed with the Cameca NanoSIMS 50 at MNHN, Paris. ${ }^{16} \mathrm{OH}^{-},{ }^{28} \mathrm{Si}^{-}$, $139{ }^{24} \mathrm{Mg}^{16} \mathrm{O}^{-}$and ${ }^{27} \mathrm{Al}^{16} \mathrm{O}^{-}$secondary ions were imaged and quantified using a $\mathrm{Cs}^{+}$primary beam. Special care 140 was dedicated to correct the contribution of water contamination: we analyzed consecutively the same 141 areas with two different primary beam intensities, $1.2 \mathrm{pA}$ and then $15 \mathrm{pA}$, in order to estimate the part of 142 OH contamination (Stephant et al., 2014). Indeed, using a correlation between the primary beam intensity 143 and the $\mathrm{OH}^{-} / \mathrm{Si}^{-}$ratio, we calculated the $\mathrm{OH}^{-} / \mathrm{Si}^{-}$at the "infinite" primary beam intensity, supposed free of 144 any $\mathrm{OH}$ contamination (see supplementary information for raw data). The primary beam was rastered over 145 a $20 \times 20 \mu \mathrm{m}^{2}$ surface area divided in $256 \times 256$ pixels with a $200 \mu \mathrm{m}$ aperture diaphragm for 60 cycles. The 146 counting time was set to $1 \mathrm{~ms} / \mathrm{px}$. Prior to the analysis, a $25 \times 25 \mu \mathrm{m}^{2}$ surface area was presputtered for 20 147 minutes using a high primary beam current (i.e. $280 \mathrm{pA}$ and $230 \mathrm{pA}$ for the session III and IV, respectively) 148 and a $750 \mu \mathrm{m}$ aperture diaphragm. The mass resolution power was $\sim 6100$ for ${ }^{16} \mathrm{OH}^{-}$and $\sim 7500$ for ${ }^{28} \mathrm{Si}^{-}$ 149 using the entrance slit ES3 and the aperture slit AS2. 39 areas were imaged in type I chondrules from Paris 150 during session III, 14 from Bishunpur and 11 from Renazzo during session IV. Vacuum in the analytical 151 chamber was $9.3 \times 10^{-10}$ Torr for session III and $1.1 \times 10^{-9}$ Torr for session IV.

152 Water concentrations in the different phases of chondrules were obtained using a calibration of $\mathrm{OH}^{-} / \mathrm{Si}^{-}$ 153 versus water concentration; water concentration is reported as $\left[\mathrm{H}_{2} \mathrm{O}\right]$ and represents $\mathrm{H}_{2} \mathrm{O}$ ppm $/ \mathrm{SiO}_{2}$ wt. \%. 154 The calibration lines were forced to the origin: using our method to estimate the $\mathrm{OH}^{-} / \mathrm{Si}^{-}$ratio at infinite 155 primary beam intensity, the surface contamination contribution on the $\mathrm{OH}^{-} / \mathrm{Si}^{-}$value is withdrawn (see the 156 discussion of this calibration in Stephant et al., 2014). Different calibrations were used depending on the 157 silicate mineralogy (Tenner et al., 2009) (Fig. 2): matrix effects are so strong that ferromagnesian minerals 158 and amphiboles show similar $\mathrm{OH}^{-} / \mathrm{Si}^{-}$ratios for very distinct water concentrations (less than $200 \mathrm{ppm}$ up 159 for the former to compare with $1 \mathrm{wt}$ \% for the latter). Thus it is crucial to precisely identify each analyzed 160 mineral to accurately quantify its water content. To this end, ${ }^{24} \mathrm{Mg}^{16} \mathrm{O}^{-28} \mathrm{Si}^{-}$and ${ }^{27} \mathrm{Al}^{16} \mathrm{O}^{-28} \mathrm{Si}^{-}$are used to 161 decipher between olivine, pyroxene and mesostasis (see supplementary information). Standard 162 measurements for each session of analysis (i.e. III and IV) are reported in supplementary information.

163 Uncertainties for each calibration line were evaluated using a code written on the $\mathrm{R}$ program (Thomen et 164 al., 2014). The reported errors on meteorite measurements are dominated by uncertainties on the 165 calibration slopes. The counting statistics on the $\mathrm{OH}^{-} / \mathrm{Si}^{-}$ratio are negligible compared to the calibration 166 slope uncertainties.

$167 \quad 3.2$ Hydrogen isotopic ratios 
Hydrogen isotopic measurements were performed by imaging $\mathrm{H}^{-}$and $\mathrm{D}^{-}$over the same areas studied for elemental analyses to provide both isotopic and elemental data at exactly the same location. Thereby, D/H images could be superimposed on elemental images. The primary beam was rastered over a $20 \times 20 \mu \mathrm{m}^{2}$ surface area divided in $256 \times 256$ pixels with a $300 \mu \mathrm{m}$ aperture diaphragm for 60 cycles with a counting time set to $1 \mathrm{~ms} / \mathrm{px}$. The primary beam intensities was $\sim 200-240 \mathrm{pA}$ for the three sessions on Paris chondrite and $29 \mathrm{pA}$ for the session IV (i.e. Bishunpur and Renazzo). Prior to each analysis, a $25 \times 25 \mu \mathrm{m}^{2}$ surface area was presputtered for 5 minutes using a high primary beam current (i.e. 230-280pA) with the $750 \mu \mathrm{m}$ aperture diaphragm. The entrance and the aperture slits were both set at the position 1 . The instrumental isotopic fractionation factor for hydrogen was determined with the set of silicate standards previously described at each session (supplementary information). During sessions I, II and III, no matrix effect was noticed for the D/H ratio using NanoSIMS at the precision of our measurements (Hu et al., 2015). However, in the session IV, a significant difference in the instrumental isotopic fractionation was observed for the amphibole and the glass standards. That can be due to the lower primary beam intensity during this session compared to the three prior sessions. The instrumental isotopic fractionation factor was also calculated as the average of these standards. The uncertainty on the instrumental isotopic fractionation corresponds to the standard deviation of terrestrial standards (see supplementary information). Errors at the $2 \sigma$ level (quadratic sum) combine the uncertainty on the instrumental mass fractionation factor and the counting statistic error on each measurement (dominated by the total number of counts detected for $\left.\mathrm{D}^{-}\right)$. The $\mathrm{D} / \mathrm{H}$ ratios are expressed in $\delta$ units (where $\delta \mathrm{D}=\left[\left(\mathrm{D} / \mathrm{H}_{\text {sample }}\right) /\left(\mathrm{D} / \mathrm{H}_{\text {sMow }}\right)-1\right]$ $\times 1000)$.

\section{4. Results}

1894.1 Water concentration in nominally anhydrous minerals (NAMs)

190 Distribution of water concentrations in olivines and pyroxenes of type I chondrules (Table 3) are presented in Figure 3 for each chondrite. Mean water concentrations in pyroxenes are $893 \pm 637 \mathrm{ppm}(1 \mathrm{SD}, \mathrm{n}=4)$, $879 \pm 536 \mathrm{ppm}(1 \mathrm{SD}, \mathrm{n}=11)$ and $791 \pm 227 \mathrm{ppm}(1 \mathrm{SD}, \mathrm{n}=8)$ for Renazzo, Bishunpur and Paris, respectively. In olivine, water concentration varies markedly between Renazzo, Bishunpur and Paris: $156 \pm 44 \mathrm{ppm}$ (1SD, n=7), 222 $\pm 123 \mathrm{ppm}(1 \mathrm{SD}, \mathrm{n}=7$ ) and $860 \pm 132 \mathrm{ppm}(1 \mathrm{SD}, \mathrm{n}=14)$, respectively. Relative uncertainties for these measurements are $\pm 25 \%$ for Paris NAMs and $\pm 50 \%$ for Bishunpur and Renazzo NAMs (supplementary information). It must be noted that significant uncertainties in the determinations of the water content in NAMs are due to the fact that our standards - being terrestrial nominally anhydrous minerals - have much lower water concentrations than those measured in Paris chondrules. This implies a large extrapolation towards large values hence larger uncertainties. Using the uncertainties on the NAMs water calibration line, the lowest estimations for pyroxene mean water concentrations become $447 \pm 318$ ppm, $439 \pm 268 \mathrm{ppm}$ and $557 \pm 147 \mathrm{ppm}$ for Renazzo, Bishunpur and Paris, respectively. Regarding the olivines, the lowest estimations for mean water concentrations are $78 \pm 22 \mathrm{ppm}, 111 \pm 61 \mathrm{ppm}$ and $645 \pm 99$ ppm, for Renazzo, Bishunpur and Paris, respectively. Therefore, Paris olivines appear to be more hydrated than those in Bishunpur and Renazzo chondrules and do contain a significant amount of water for a nominally anhydrous mineral. For pyroxenes, Bishunpur and Renazzo exhibit a more scattered distribution than Paris. The small numbers of chondrule analyzed for Bishunpur (i.e. 4) and Renazzo (i.e. meteorites. Moreover, water concentrations in Paris chondrules were determined in epoxy-free sections 
209 (session III), allowing us to rule out a significant contribution from the epoxy in the $\mathrm{OH}^{-}$signal and a

210 subsequent bias in the determination of the water content (Aubaud et al., 2007).

2114.2 Hydrogen isotopic ratio in chondrules

212 4.2.1 Comparison between Paris, Renazzo and Bishunpur

213 Distribution of the hydrogen isotopic composition of minerals in chondrules in Paris, Renazzo and

214 Bishunpur (Table 3) are shown in Figure 4. The mean $\delta \mathrm{D}$ value for these three meteorites fall within the

215 terrestrial domain (Lécuyer et al., 1998). Paris exhibits a wide spread of $\delta \mathrm{D}$ from $-398 \pm 23 \%$ o to $366 \pm 35 \%$ o

216 (i.e. covering a range of $764 \%$ ) with a mean value of $-88 \pm 141 \%$ o ( $2 \mathrm{SD}, \mathrm{n}=70$ ). In Paris, the $\delta \mathrm{D}$ of the

217 surrounding matrix is $-69 \pm 32 \%$. The possible contamination of the Paris samples by terrestrial moisture

218 can be ruled out since chondrules show both enrichment and depletion of deuterium relative to the

219 terrestrial value. The Paris mounts without epoxy (i.e. session II and III; chondrules A, B, D, E, 1 and 7)

220 shows the largest range of $\delta \mathrm{D}$ values. In Renazzo, the $\delta \mathrm{D}$ in olivines, pyroxenes and mesostases range from $-212 \pm 125$ to $15 \pm 156 \%$ o with a mean value of $-131 \pm 115 \%$ o $(2 \mathrm{SD}, \mathrm{n}=21)$. An image recorded in the matrix gives a value of $316 \pm 202 \%$ o. These determinations are consistent with previous studies in Renazzo (Deloule and Robert, 1995) showing that the matrix is enriched in deuterium (-37 to $733 \%$ ) relative to chondrules (-294 to $284 \%$ ). Bishunpur minerals range from $-166 \pm 133 \%$ o to $137 \pm 176 \%$ with a mean value of $-66 \pm 148 \%$ o ( $2 \mathrm{SD}, \mathrm{n}=16$ ). This range is significantly smaller compared to previous studies on Bishunpur chondrules: $-371 \% \circ<\delta \mathrm{D}<1934 \%$ (Deloule and Robert, 1995; Deloule et al., 1998). We will focus our attention in the upcoming discussion on the emblematic case of Paris for which the $\delta \mathrm{D}$ variations reach

$228764 \%$.

4.2.2 Inter-chondrule variations in Paris

A broad inter-chondrule isotopic distribution is observed in Paris: in the mesostasis $-292 \pm 32 \%$ o $<\delta \mathrm{D}<366 \pm 35 \%$ o with a mean value $\delta \mathrm{D}=-44 \pm 346 \%$ ( $2 \mathrm{SD}, \mathrm{n}=26$ ), in olivines $-398 \pm 23 \%$ o $<\delta \mathrm{D}<76 \pm 36 \%$ o with a mean value of $-136 \pm 258 \%$ o ( $2 \mathrm{SD}, \mathrm{n}=24)$ and in pyroxenes $-342 \pm 23 \% \circ<\delta \mathrm{D}<155 \pm 53 \%$ o with a mean value of $-84 \pm 250 \%$ o ( $2 \mathrm{SD}, \mathrm{n}=20)$. The $\delta \mathrm{D}$ in Paris chondrules spans over a range of $764 \%$; this corresponds to a large isotopic fractionation that is never observed in terrestrial samples. Pyroxenes and olivines exhibit the same range. Mesostasis seems to be slightly enriched in deuterium compared to adjacent olivine and pyroxene. However, individual chondrules exhibit more complex variations as discussed hereafter.

238 4.2.3 Intra-chondrule variations in Paris

239 In addition to the broad range of $\delta \mathrm{D}$ observed among chondrules, intra-chondrule heterogeneities are also 240 pronounced in Paris. Indeed, an isotopic variation of $658 \%$ is observed between the different phases of the chondrule $\mathrm{E}$ and up to $664 \%$ o for the chondrule A. More surprisingly, isotopic variation among olivines in chondrule A reaches $454 \%$ in less than $\sim 200 \mu \mathrm{m}$. In Figure 5, NanoSIMS images of $\mathrm{AlO}^{-} / \mathrm{Si}^{-}$and D/H of a $20 \times 20 \mu \mathrm{m}^{2}$ area in the chondrule A are shown. Olivine and mesostasis that are contiguous exhibit a difference in $\delta \mathrm{D}$ of $317 \%$ o with no visible gradient (the NanoSIMS resolution does not exceed $\sim 500 \mathrm{~nm}$ ). In most cases, the mesostasis is enriched in deuterium compared to olivine and pyroxene (chondrules A, B, $\mathrm{D}, \mathrm{E}, \mathrm{A}, 7,9$ ) with the exception of chondrules 24,6 and 27. As such, no systematic between mesostases $\delta \mathrm{D}$ and silicates $\delta \mathrm{D}$ is observed, suggesting there is no equilibrium between mesostasis and silicates 
minerals. Futhermore, no correlation is observed between the degree of aqueous alteration experienced by the chondrule, as revealed by its petrology, and the $\delta \mathrm{D}$ distribution of the chondrule. In the less altered chondrule (19), there is no variation, within errors, of the $\delta \mathrm{D}$ value between the mesostasis and olivine and pyroxene (i.e. $-34 \pm 79 \%$ on average, 2SD). However, chondrules A, E and 7 exhibit a low degree of aqueous alteration illustrated by abundant metal grains and they show a large isotopic heterogeneity between their minerals. In addition, chondrule 27 is heavily altered (its mesostasis is altered into phyllosilicates) while $\delta \mathrm{D}$ variations do not exceed $232 \%$ o between mesostasis and minerals. An important point to notice is that chondrules $\mathrm{A}, \mathrm{E}$ and 1 , showing the largest range of $\delta \mathrm{D}$ values, were all measured in epoxy-free mounts. As a conclusion of this isotopic survey, $\delta \mathrm{D}$ variations are intrinsic to each chondrule but not related to their degree of aqueous alteration.

\section{5. Discussion}

5.1 Implication of the $\delta \mathrm{D}$ distribution for chondrule formation models

\subsection{1 $\delta \mathrm{D}$ fractionation among coexisting minerals}

262 The isotopic fractionation coefficient $\alpha$ between two phases corresponds to the ratio of their $\mathrm{D} / \mathrm{H}$ values.

263 Figure 6 reports the isotopic fractionation coefficients $\alpha$ between olivine and mesostasis versus those 264 between pyroxene and mesostasis, reported as $10^{3} \times \ln \alpha$ in per mil. Fractionation coefficients are calculated for adjacent phases (see supplementary information). Therefore, each point corresponds to a NanoSIMS image containing the 3 phases in a $20 \times 20 \mu \mathrm{m}^{2}$ surface area. A trend is observed with both positive and negative values. The slope of the correlation is not far from unity, indicating that pyroxene and olivine have similar $\delta \mathrm{D}$. The important point to notice is the large range of fractionation coefficient values (i.e. $10^{3} \times \ln \alpha$ ranging for $-431 \%$ o to $+283 \%$ o). This correlation requires a process that would generate a large fractionation factors between minerals during chondrule history. Furthermore, this correlation has no link to the degree of aqueous alteration and is not simply related to hydrothermal alteration, which may imply that chondrules followed different fractionation history. conditions

The observed fractionation factors are too large to account for an isotopic fractionation at equilibrium during $\mathrm{H}$ isotopic exchange between $\mathrm{H}$-bearing minerals and water. Significant intra-chondrules heterogeneities among the same phases are up to $764 \%$. In terrestrial environments, such variations are never observed among alteration products and fractionation factors between minerals and water are restricted to 60\%o (Saccocia et al., 2009). This should be regarded as clear evidence against a simple equilibrium isotope fractionation between phases of the same chondrule.

\subsubsection{Modelling the chondrule alteration by an isotopically homogeneous fluid.}

NAMs (i.e. olivine and pyroxenes) are either enriched or depleted in D relative to the mesostasis (Fig. 6). This suggests there is no equilibrium between mesostasis and these minerals. This results in a crossover rarely observed in natural environment, which should be regarded as a dependable constraint for chondrules formation models. We first discuss common geochemical situations that cannot yield such a 
The progressive isotopic re-equilibration of the minerals with the mesostasis by diffusion of an external fluid to the chondrule cannot account for the isotopic crossover observed in the Figure 6 since isotopic fractionation will be unidirectional (Kyser and O'Neil, 1984). In other terms, the expected correlation for diffusion in the Figure 6 is either enriched or depleted relative to 0 but never on both sides.

However, we considered here diffusion by a reservoir of water with homogeneous isotope composition. Bonal et al. (2013) have shown that the $\delta \mathrm{D}$ of the matrix water is highly heterogeneous at the micrometer scale in CR chondrite. Piani et al. (2015) have shown that water-ice precursors with a large range of $\delta \mathrm{D}$ compositions could have accreted into the parent body and been responsible for matrix $\delta \mathrm{D}$ heterogeneities at the micron scale. Secondary processes on the parent body have also been suggested to explain this spatial variability (Alexander et al., 2010; Alexander et al., 2012). This $\delta$ D spatial heterogeneity at a small scale could potentially have induced the heterogeneities observed among single chondrules. However, this model holds three issues. (1) The fractionation coefficients between ferromagnesians (i.e. olivine and pyroxene) and mesostasis show significant variations (cf. Fig. 6). This means that the $\delta \mathrm{D}$ of the mesostasis can be distinct from that in the pyroxene or olivine next to this mesostasis. Even if the aqueous alteration occurs at the micrometer scale, phases having common boundaries should record a similar $\delta \mathrm{D}$ value; plus or less the isotopic fractionation at equilibrium between phases (Saccocia et al., 2009). (2) The $\delta \mathrm{D}$ measured in the matrix covers a more restricted range (i.e. $-66 \pm 70 \%$; $2 \mathrm{SD}$ ) compared to the broad distribution of $\delta \mathrm{D}$ in chondrule phases; (3) This model does not account for the high water content in olivines, as it seems quite unrealistic to incorporate a minimum of $645 \mathrm{ppm} \mathrm{H}_{2} \mathrm{O}$ inside an olivine at chondritic parent body conditions of pressure and temperature. This problem will be discussed in the next section.

310 Hence, hydration of the chondrule by parent body water does not fit the requirements to explain the isotopic crossover observed in the Figure 6. However, as shown in the next section, it may be explained by the evaporation of $\mathrm{H}$ before the formation of the parent body, provided that this $\mathrm{H}$ was present in chondrules at the moment of their formation.

314 5.2.3. Loss of $\mathrm{H}$ from chondrules during their cooling in the gas phase.

315 Here we propose that distillation of $\mathrm{H}$ took place during the melting and the cooling of the chondrule in the gas phase. This outgassing model has two implications: (1) the initial $[\mathrm{H}]$ concentration and (2) the degree of distillation caused by $\mathrm{H}_{2}$ escape can vary from chondrule to chondrule. As the analyzed chondrules show various textural and petrological features, there is no reason that they share common initial water content and that they underwent the same degree of distillation.

Rayleigh distillation induced by the loss of $\mathrm{H}_{2}$ from melted chondrules can be written as:

$$
D / H(t)_{\text {phase }}=D / H(0)_{\text {phase }} \times f_{\text {phase }}\left(\alpha_{(H 2-H 2 O)}-1\right)
$$

With $\mathrm{D} / \mathrm{H}(0)$ the initial hydrogen isotope ratio of the mineral; $\mathrm{D} / \mathrm{H}(\mathrm{t})$ the hydrogen isotopic ratio at instant $\mathrm{t}$ and $f_{\text {phase }}$ is the remaining fraction of $\mathrm{H}$ in the mineral (i.e. from 1 to 0 ); $\alpha_{H 2-H 2 O}$ is the isotopic fractionation between $\mathrm{H}_{2}$ and $\mathrm{H}_{2} \mathrm{O}$ in phases. The lowest measured value on chondrule phases i.e. for $\delta \mathrm{D}=$ $-398 \%$ is used to set $D / H(0)_{\text {phase }}$. We assume that each phase follows its own $f$ Rayleigh coefficient i.e. 
that NAMs and mesostasis evolve independently since they do not share the same level of advancement of the diffusion for $\mathrm{H}$ species (Ingrin and Blanchard, 2006) and initial water concentration. Indeed, mesostasis can be either depleted or enriched relative to olivine and pyroxene, function of their relative degree of degassing. Calculations are reported in Figure 6 for $f_{\text {phase }}$ values randomly generated for mesostasis and for NAMs. These calculations reproduce the wide range of isotopic fractionation variations with $\alpha_{H 2-H 2 O}$ value of $\approx 0.9$ for olivine and pyroxene and $\approx 0.85$ for mesostasis. These $\alpha$ values are markedly different from unity and therefore consistent with the large $\mathrm{H}_{2}-\mathrm{H}_{2} \mathrm{O}$ isotopic fractionation factor (Simon et al., 2011). From these $\alpha$ values, we calculate a reducing temperature of the system during the isotope fractionation around $900-1100{ }^{\circ} \mathrm{C}$ (Simon et al., 2011).

An alternative scenario could involve the reduction of water during parent body processes (Alexander et al., 2010). Lécluse and Robert (1994) showed that the isotope exchange between $\mathrm{H}_{2} \mathrm{O}$ and $\mathrm{H}_{2}$ is still fast down to $200-300^{\circ} \mathrm{C}$, i.e. at hydrothermalism temperatures. If we consider that a distillation took place around $150^{\circ} \mathrm{C}$ in the parent body (Clayton and Mayeda, 1999; Guo and Eiler, 2007), the fractionation factor between $\mathrm{H}_{2}$ and $\mathrm{H}_{2} \mathrm{O}$ should be far $\left(\alpha_{\mathrm{H}_{2-H} \mathrm{O}} \approx 0.3\right.$, by extrapolating from Simon et al., 2011) from our calculated value $\left(\alpha_{H 2-H 2 O} \approx 0.9\right)$. In other terms, it seems unrealistic to argue that water reduction took place on the parent body while the hydrogen isotopic system registered temperatures around $900-1100{ }^{\circ} \mathrm{C}$. We thus propose that chondrules have degassed their juvenile water prior to their incorporation in their parent body, presumably in the nebula, following the reduction of their water at temperature around 900$1100^{\circ} \mathrm{C}$

The lack of correlation between water content and the $\delta \mathrm{D}$ demonstrates that each chondrules contained heterogeneous initial water concentrations or $\delta \mathrm{D}$ or both. As analyzed chondrules are of different textural types, we can assume that each chondrule gets its own initial water content.

\subsection{Incorporation of high water contents in NAMs}

\subsubsection{Data on Earth}

It is now established that nominally anhydrous minerals are a major host for water in terrestrial mantle (Bell and Rossman, 1992; Bolfan-Casanova, 2005; Hirschmann et al., 2005; Peslier, 2010). Martin and Donnay (1972) were the first to propose a water incorporation model based on $\mathrm{OH}$ ions replacing $\mathrm{O}$ in the structure of pyroxenes. Water storage has been extensively studied in NAMs. Natural pyroxene water concentrations range from few 10 s up to $\sim 1100 \mathrm{ppm}$ of $\mathrm{H}_{2} \mathrm{O}$, depending on the geological occurrence (Rauch and Keppler, 2002; Skogby, 2006; Sundvall and Stalder, 2011). Natural olivine contains significantly less water than pyroxene with contents ranging roughly between few and 400 ppm of $\mathrm{H}_{2} \mathrm{O}$ (Bell and Rossman, 2003; Beran and Libowitzky, 2006). Measured water concentrations in NAMs of Paris chondrules (mostly olivines) are markedly higher than those in terrestrial ones. Thus water contents measured in olivine seem too high to come only from water in olivine.

However, several experiments show that olivine can incorporate significant amount of water at high pressure, high temperature (Kohlstedt et al., 1996; Mosenfelder et al., 2011; Ohtani et al., 2001). Férot and Bolfan-Casanova (2012) measured olivine water contents of $4690 \pm 1655 \mathrm{ppm}$ for experiments performed at $9 \mathrm{GPa}$ and $1175{ }^{\circ} \mathrm{C}$. Smyth et al. (2006) found water solubility in olivines up to $8900 \mathrm{ppm}$ at $12 \mathrm{GPa}$ and $1250^{\circ} \mathrm{C}$. 
OH-rich inclusions in olivines and pyroxenes of magmatic origin could account for the large content we determine. For instance, Khisina et al. (2001) have shown that hydrogen incorporation in olivine exists in two modes: intrinsic mode into olivine structure (Wright, 2006) and extrinsic incorporation as nanometersized inclusions of $\mathrm{OH}$ bearing silicates. In pyroxene, hydroxyl can occur in the form of narrow lamellae of amphibole (Skogby et al., 1990; Veblen and Buseck, 1981).

\subsubsection{Implications for chondrule olivines of Paris}

From the experimental data on Earth's olivine, the striking water contents measured in Paris olivines could suggest that olivines were formed at high-pressure, high-temperature conditions in order to incorporate such amount of water; assuming that this water is under the form of hydroxylated groups in the structure of olivines. The model proposed by Libourel and Krot (2007) suggested that olivines are inherited from mantle planetesimals fragmented by impacts. In this scenario, mantle olivine can incorporate large amounts of water under conditions of high pressure and high temperature. As suggested by Libourel and Krot, pyroxenes could result from the destabilization of olivine caused by the incorporation of $\mathrm{SiO}$ diffusing from the gas phase. Qualitatively, this model accounts for the similar $\delta \mathrm{D}$ values in the pyroxene and in its parent olivine. Nevertheless, there are restrictions to this hypothesis. First, this scenario by Libourel and Krot is based on chondrules having a granoblastic texture that is not found in all our studied chondrules. Secondly, the kind of high pressure needed to incorporate a minimum of $645 \mathrm{ppm}$ of water in olivine seems difficult to reconcile with a small parent body.

The speciation of hydrogen is not known through NanoSIMS analyses and it is limited by its spatial resolution $(100 \mathrm{~nm})$. Nanometer-sized inclusions cannot be identified by NanoSIMS imaging. We assumed that the hydrogen occurs under the form of hydroxylated groups in the chondrule olivines. However, glass inclusions in olivines can be found in any type of chondrules (Varela et al., 2002; Florentin et al., 2016). These inclusions occur at the micrometer scale and their water contents should be more similar to the mesostasis one, in the range of few wt. $\% \mathrm{H}_{2} \mathrm{O}$. Indeed, such inclusions should appear on our NanoSIMS images of $\mathrm{AlO}^{-} / \mathrm{Si}^{-}, \mathrm{MgO}^{-} / \mathrm{Si}^{-}$and $\mathrm{OH}^{-} / \mathrm{Si}^{-}$, as we have a resolution down to $100 \mathrm{~nm}$ at $1.2 \mathrm{pA}$. We do not observe any variations in these three ratios during the duration of our analyses, meaning that we do not cross any glass inclusions of this type.

We propose that type I chondrules precursors could be composed of glassy grains, clays minerals or altered ferromagnesians, i.e. hydrous matrix-like material. These precursors would have been incompletely degassed after chondrule cooling and before incorporation into the parent body. Water should have been incorporated into chondrules before their accretion into the parent body, as it seems unrealistic to add a large amount of water in chondrule olivines at parent body conditions.

The Rayleigh distillation model seems to indicate that chondrules would have degassed their primordial hydrogen, distinct from the alteration water, resulting from reduction of water into $\mathrm{H}_{2}$ at $\simeq 900^{\circ} \mathrm{C}$. Still, there are some interesting unsolved issues: of this source could be as low as $-398 \%$, i.e. the lower $\delta \mathrm{D}$ value measured in chondrule phases. This value is markedly distinct from both the nebula $\mathrm{H}_{2}$ and the mean chondrite 
hydrogen isotopic signature. There are few components with such low $\delta \mathrm{D}$ among solar system objects. The unique organic matter contained in the Abee meteorite in one of them (Remusat et al. 2012; Yang and Epstein 1983). This material signs the occurrence, in the early solar system, of a $\mathrm{H}$-reservoir that was at isotopic equilibrium with molecular $\mathrm{H}_{2}$ in the neutral environment (Lécluse and Robert, 1994). This source of $\mathrm{H}$ could also be responsible of the end-member $\delta \mathrm{D}$ value advocated to interpret the linear variations observed at the scale of the bulk $\mathrm{CCs}$ in a $\mathrm{D} / \mathrm{H}$ vs. $\mathrm{C} / \mathrm{H}$ diagram: at $\mathrm{C} / \mathrm{H}=0, \delta \mathrm{D}=-$ $444 \pm 23 \%$ o (Alexander et al., 2012). According to the present study, in bulk CCs, organic free minerals (chondrules) could be the carriers of a H-reservoir with a low $\delta \mathrm{D}$.

This model implies that NAMs had a higher water concentration before the distillation since $\mathrm{H}_{2}$ was lost from chondrule. Therefore chondrule precursors were hydrated before their melting/crystallization into the form of chondrules and were incompletely outgassed during the rapid cooling of the chondrules. Incorporation of high water content could have been achieved because chondrule precursors included hydroxylated minerals.

It should be emphasized that the presently proposed distillation model does not preclude a late alteration (hydration) of chondrules by circulating parent body water causing a limited homogenization of the initial chondrule $\delta \mathrm{D}$ values. Indeed, - if the fluid was isotopically homogenous - the isotope fractionation between minerals and water is limited to $50 \%$ and thus should not have significantly altered the observed chondrule $\delta \mathrm{D}$ distribution that spars over $764 \%$.

\section{Acknowledgements}

We are grateful to B. Zanda and to the meteorite collection of the Muséum National d'Histoire Naturelle for providing samples of Paris, Renazzo and Bishunpur. We also thank P. Cartigny, E. Deloule and K. Koga for providing standards. We thank the reviewers and the associate editor A.N. Krot for helpful discussion and comments. The National NanoSIMS facility at the Muséum National d'Histoire Naturelle was established by funds from the CNRS, Région Île de France, Ministère délégué à l'Enseignement supérieur et à la Recherche, and the Muséum itself.

\section{References}

Alexander C.M.O.D., Barber D.J., and Hutchison R. (1989) The microstructure of Semarkona and Bishunpur. Geochim. Cosmochim. Acta 53, 3045-3057.

Alexander C.M.O.D., Bowden R., Fogel M.L., Howard K.T., Herd C.D.K. and Nittler L.R. (2012) The Provenances of Asteroids, and Their Contributions to the Volatile Inventories of the Terrestrial Planets. Science 337, 721-723.

Alexander C.M.O.D., Howard K.T., Bowden R., and Fogel M.L. (2013) The classification of CM and CR chondrites using bulk H, C and N abundances and isotopic compositions. Geochim. Cosmochim. Acta 123, 244-260.

Alexander C.M.O.D., Newsome S.D., Fogel M.L., Nittler L.R., Busemann H., and Cody G.D. (2010) Deuterium enrichments in chondritic macromolecular material-Implications for the origin and evolution of organics, water and asteroids. Geochim. Cosmochim. Acta 74, 4417-4437.

Aubaud C., Withers A.C., Hirschmann M.M., Guan Y., Leshin L.A. Mackwell S.J. and Bell D.R. (2007) Intercalibration of FTIR and SIMS for hydrogen measurements in glasses and nominally anhydrous minerals. Amer. Mineral. 92, 811-828. 
452

453

454

455

456

457

458

459

460

461

462

463

464

465

466

467

468

469

470

471

472

473

474

475

476

477

478

479

480

481

482

483

484

485

486

487

488

489

490

491

492

493

494

495

496

497

498

499

500

501

Beck P., Quirico E., Montes-Hernandez G., Bonal L., Bollards J., Orthous-Daunay F.-R., Howard K.T., Schmitt B., Brissaud O., Deschamps F., Wunder B. and Guillot S. (2010) Hydrous mineralogy of CM and CI chondrites from infrared spectroscopy and their relationship with low albedo asteroids. Geochim. Cosmochim. Acta 74(16), 4881-4892.

Bell D.R. and Rossman G.R. (1992) Water in Earth's mantle: the role of nominally anhydrous minerals. Science 255, 1391-1397.

Bell D.R. and Rossman G.R. (2003) Hydroxide in olivine: a quantitative determination of the absolute amount and calibration of the IR spectrum. J. Geophys. Res. 108, 1978-2012.

Beran A. and Libowitzky E. (2006) Water in natural mantle minerals II: olivine, garnet and accessory minerals. Rev. Mineral. Geochem. 62, 169-191.

Bischoff A. (1998) Aqueous alteration of carbonaceous chondrites: evidence for preaccretionary alteration. A review. Meteorit. Planet. Sci. 33, 1113-1122.

Boato G. (1954) The isotopic compositionof hydrogen and carbon in the carbonaceous chondrites. Geochim. Cosmochim. Acta 6, 209-220.

Bolfan-Casanova N. (2005) Water in the Earth's mantle. Mineral. Mag. 69, 229-257.

Bonal L., Alexander C.M.O.D., Huss G.R., Nagashima K. and Quirico E. (2013) Hydrogen isotopic composition of the water in CR chondrites. Geochim. Cosmochim. Acta 106, 111-133.

Brearley A.J. (2003) Nebular versus Parent-body processing, in Meteorites, Comets and Planets: Treatise in Cosmochemistry vol.1 (eds. Davis A.M., Holland, H.D. and Turekan, K.K.) Elsevier-Pergamon, Oxford.

Browning L.B., McSween H.Y. and Zolensky M.E. (1996) Correlated alteration effects in CM carbonaceous chondrites. Geochim. Cosmochim. Acta 60, 2621-2633.

Ciesla F.J., Lauretta D.S., Cohen B.A. and Hood L.L. (2003) A Nebular Origin for Chondritic FineGrained Phyllosilicates. Science 299, 549-552.

Clayton R. N. and Mayeda T. K. (1999) Oxygen isotope studies of carbonaceous chondrites. Geochim. Cosmochim. Acta 63, 2089-2104.

Clog M. (2010) Concentration et composition isotopique de l'hydrogène dans le manteau terrestre. Ph.D. thesis.

de Lew S., Rubin A.E., Schmitt A.K. and Wasson J.T. (2009) 53Mn-53Cr systematics of carbonates in CM chondrites: implications for the timing and duration of aqueous alteration. Geochim. Cosmochim. Acta 73, 7433-7442.

Deloule E., France-Lanord C. and Albarède F. (1991) D/H analysis of minerals by ion probe in Stable isotope Geochemistry : a tribute to Samuel Epstein (eds Taylor H.P., O'Neil J.R. and Kaplan I.R.) Geochem. Soc. Spec. Publ. 3, 53-62

Deloule E. and Robert F. (1995) Interstellar water in meteorites? Geochim. Cosmochim. Acta 59, 46954706.

Deloule E., Robert F. and Doukhan J.C. (1998) Interstellar hydroxyl in meteoritic chondrules: Implications for the origin of the water in the inner solar system. Geochim. Cosmochim. Acta 62, 33673378.

Eiler J.M. and Kitchen N. (2004) Hydrogen isotope evidence for the origin and evolution of the carbonaceous chondrites. Geochim. Cosmochim. Acta 68(6), 1395-1411.

Férot A. and Bolfan-Casanova N. (2012) Water storage capacity in olivine and pyroxene to 14GPa: implications for the water content of the Earth's upper mantle and nature of seismic discontinuities. Earth Planet. Sci. Lett. 349-350, 218-230.

Fieni C., Bourot-Denise M., Pellas P. and Touret J. (1978) Aqueous fluid inclusions in feldspars and phosphates from Peetz chondrite. Meteoritics 13, 460.

Florentin L., Faure F., Tissandier L., Deloule E. and Lequin D. (2016) Heated olivine-hosted glass inclusions from Allende CV3 meteorite: insight on chondules origin. 47th Lun. Planet. Sci. Conf. \#1863.

Fujiya W., Sugiura N., Hotta H., Ichimura K. and Sano Y. (2012) Evidence for the late formation of hydrous asteroids from young meteoritic carbonates. Nature Commun. 3, 1-6. 
502

503

504

505

506

507

508

509

510

511

512

513

514

515

516

517

518

519

520

521

522

523

524

525

526

527

528

529

530

531

532

533

534

535

536

537

538

539

540

541

542

543

544

545

546

547

548

549

550

551
Garenne A., Beck P., Montes-Hernandez G., Chiriac R., Toche F., Quirico E., Bonal L. and Schmitt B. (2014) The abundance and stability of "water" in type 1 and 2 carbonaceous chondrites (CI, CM and CR). Geochim. Cosmochim. Acta 137, 93-112.

Greenwood R.C., Franchi I.A., Pont S., Lorand J.-P., Cournède C., Gattacceca J., Rochette P., Kuga M., Marrocchi Y. and Marty B. (2014) The Paris meteorite, the least altered CM chondrite so far. Geochim. Cosmochim. Acta 124, 190-222.

Guo W. and Eiler J. M. (2007) Temperatures of aqueous alteration and evidence for methane generation on the parent bodies of the CM chondrites. Geochim. Cosmochim. Acta 71, 5565-5575.

Hanowski N.P. and Brearley A.J. (2001) Aqueous alteration of chondrules in the CM carbonaceous chondrite, Allan Hills 81002: implications for parent body alteration. Geochim. Cosmochim. Acta 65, 495518.

Hauri E.H., Gaetani G.A. and Green T.H. (2006) Partitioning of water during melting of the Earth's upper mantle at H2O-undersaturated conditions. Earth Planet. Sci. Lett. 248, 715-734

Hewins R.H., Bourot-Denise M., Zanda B., Leroux H., Barrat J.-A., Humayun M., Göpel C.,

Hirschmann M.M., Aubaud C. and Withers A.C. (2005) Storage capacity of $\mathrm{H}_{2} \mathrm{O}$ in nominally anhydrous minerals in the upper mantle. Earth Planet. Sci. Lett. 236, 167-181.

Howard K.T., Benedix G.K., Bland P.A. and Cressey G. (2011) Modal mineralogy of CM chondrites by X-ray diffraction (PSD-XRD): Part 2. Degree, nature and settings of aqueous alteration. Geochim. Cosmochim. Acta 75, 2735-2751.

Hu S., Lin Y., Zhang J., Hao J., Yang W. and Deng L. (2015) Measurements of water content and D/H ratio in apatite and silicate glasses using a NanoSIMS 50L. J. Analyt. Atom. Spec. 30, 967-978.

Ingrin J. and Blanchard M. (2006) Diffusion of hydrogen in minerals. Rev. Mineral. Geochem. 62, 291320.

Kerridge J.F. (1985) Carbon, hydrogen and nitrogen in carbonaceous chondrites: Abundances and isotopic compositions in bulk samples. Geochim. Cosmochim. Acta 49, 1707-1714.

Khisina N.R., Wirth R., Andrut M. and Ukhanov A.V. (2001) Extrinsic and intrinsic mode of hydrogen occurrence in natural olivines: FTIR and TEM investigation. Phys. Chem. Min. 28, 291-301.

Koga K., Hauri E., Hirschmann M. and Bell D. (2003) Hydrogen concentration analyses using SIMS and FTIR : comparions and calibration for nominally anhydrous minerals. Geochem. Geoph. Geosys. 4(2).

Kohlstedt D.L., Keppler H. and Rubie D.C. (1996) Solubility of water in the $\alpha, \beta$ and $\gamma$ phases of $(\mathrm{Mg}, \mathrm{Fe})_{2}$ $\mathrm{SiO}_{4}$. Contrib. Mineral. Petrol. 123, 345-357.

Kyser T.K. and O'Neill J.R. (1984) Hydrogen isotope systematics of submarine basalts. Geochim. Cosmochim. Acta 48, 2123-2133.

Lécluse C. and Robert F. (1994) Hydrogen isotope exchange reaction rates : origin of water in

the inner solar system. Geochim. Cosmochim. Acta 58(13), 2927-2939.

Lécuyer C., Gillet P. and Robert F. (1998) The hydrogen isotope composition of seawater and the global water cycle. Chem. Geol. 145(3-4), 249-261.

Libourel G. and Krot A.N. (2007) Evidence for the presence of planetesimal material among the precursors of magnesian chondrules of nebular origin. Earth Planet. Sci. Lett. 254, 1-8.

Marrocchi Y., Gounelle M., Blanchard I., Caste F. and Kearsley T. (2014) The Paris CM chondrite: Secondary minerals and asteroidal processing. Meteorit. Planet. Sci. 49(7), 1232-1249.

Martin R.F. and Donnay G. (1972) Hydroxyl in the mantle. Amer. Mineral. 57, 554-570.

Marty B. (2012) The origins and concentrations of water, carbon, nitrogen and noble gases on Earth. Earth Planet. Sci. Lett. 313-314, 56-66.

Mosenfelder J.L., Le Voyer M., Rossman G.R., Guan Y., Bell D.R., Asimow P.D. and Eiler J.M. (2011) Analysis of hydrogen in olivine by SIMS: evaluation of standards and protocol. Amer. Mineral. 96, 17251741.

Ohtani E., Toma M., Litasov K., Kubo T. and Suzubi A. (2001) Stability of dense hydrous magnesium silicate phases and water storage capacity in the transition zone and lower mantle. Phys. Earth Planet. Int. 124, 105-117. 
552

553

554

555

556

557

558

559

560

561

562

563

564

565

566

567

568

569

570

571

572

573

574

575

576

577

578

579

580

581

582

583

584

585

586

587

588

589

590

591

592

593

594

595

596

597

598

599

600

Peslier A.H. (2010) A review of water contents of nominally anhydrous natural minerals in the mantles of Earth, Mars and the Moon. J. Volcanol. Geotherm. Res. 197, 239-258.

Piani L., Robert F. and Remusat L. (2015) Micron-scale D/H heterogeneity in chondrite matrices: A signature of the pristine solar system water? Earth Planet. Sci. Lett. 415, 154-164.

Rauch M. and Keppler H. (2002) Water solubility in orthopyroxene. Contrib. Mineral. Petrol. 143, 525536.

Remusat L., Rouzaud J.N., Charon E., Le Guillou C., Guan Y. and Eiler J.M. (2012) D-depleted organic matter and graphite in the Abee enstatite chondrite. Geochim. Cosmochim. Acta 96, 319-335.

Robert F. (2003) The D/H ratio in chondrites. Space Sci. Rev. 206, 87-101.

Robert F. (2006) Solar System Deuterium/Hydrogen Ratio, in Meteorites and the Early Solar System II (eds. Lauretta D.S. and McSween H.Y.) University of Arizona Press.

Rubin A.E., Trigo-Rodríguez J.M., Huber H., Wasson J.T. (2007) Progressive aqueous alteration of CM carbonaceous chondrites. Geochim. Cosmochim. Acta 71, 2361-2382.

Saccocia P.J., Seewald J.S. and Shanks III W.C. (2009) Oxygen and hydrogen isotope fractionation in serpentine-water and talc-water systems from 250 to $450{ }^{\circ} \mathrm{C}, 50 \mathrm{MPa}$. Geochim. Cosmochim. Acta 73, 6789-6804.

Simon L., Lécuyer C., Martineau F. and Robert F. (2011) Experimental qtudy of D/H fractionation between water and hydrogen gas during the oxidation of Fe-bearing silicates at high temperatures $\left(600{ }^{\circ} \mathrm{C}\right.$ - $\left.1200{ }^{\circ} \mathrm{C}\right)$. Cent. Euro. Geol. 54, 81-93.

Skogby H. (2006) Water in natural matle minerals I: pyroxenes. Revi. Mineral. Geochem. 62, 155-167.

Skogby H., Bell D.R. and Rossman G.R., 1990. Hydroxide in pyroxenes: variations in the natural environment. Amer. Mineral. 75, 764-774.

Smyth J.R., Frost D.J., Nestola F., Holl C.M. and Bromiley G. (2006) Olivine hydration in the deep upper mantle: effects of temperature and silica activity. Geophys. Res. Lett. 33, L15301.

Stephant A., Remusat L., Thomen A. and Robert F. (2014) Reduction of OH contamination in quantification of water contents using NanoSIMS imaging. Chem. Geol. 380, 20-26.

Sundvall R. and Stalder R. (2011) Water in upper mantle pyroxene megacrysts and xenocrysts: a survey study. Amer. Mineral. 96, 1215-1227.

Tenner T.J., Hirschmann M.M., Withers A.C. and Hervig R.L. (2009) Hydrogen partitioning between nominally anhydrous upper mantle minerals and melt between 3 and $5 \mathrm{GPa}$ and applications to hydrous peridotite partial melting. Chem. Geol. 262, 42-56.

Thomen A., Robert, F. and Remusat L. (2014) Determination of the nitrogen abundance in organic materials by NanoSIMS quantitative imaging. J. Analyt. Atom. Spec. 29, 512-519.

Van Schmus W.R. and Wood J.A. (1967) A chemical-petrologic classification for the chondritic meteorites. Geochim. Cosmochim. Acta 31, 747-765.

Varela M.E., Kurat G., Hoppe P. and Brandstätter F. (2002) Chemistry of glass inclusions in olivines of the CR chondrites Renazzo, Acfer 182, and El Djouf 001. Geochim. Cosmochim. Acta 66(9), 1663-1679, Veblen D.R. and Buseck P.R. (1981) Hydrous pyriboles and sheet silicates in pyroxenes and uralites: intergrowth microstructures and reaction mechanisms. Amer. Mineral. 66, 1107-1134.

Walsh K.J., Morbidelli A., Raymond S.N., O'Brien D.P. and Mandell A.M. (2011) A low mass for Mars from Jupiter's early gas-driven migration. Nature 475, 206-209.

Weisberg M.K., Prinz M., Clayton R.N. and Mayeda T.K. (1993) The CR (Renazzo-type) carbonaceous chondrite group and its implications. Geochim. Cosmochim. Acta 57, 1567-1586.

Wright K. (2006) Atomistic models of $\mathrm{OH}$ defects in nominally anhydrous minerals. Rev. Mineral. Geochem. 62, 67-83.

Yang J. and Epstein S. (1983) Interstellar organic matter in meteorites. Geochim. Cosmochim. Acta 47, 2199-2216.

Young E.D., Ash R.D., Philip E. and Rumble III D. (1999) Fluid flow in chondritic parent bodies: deciphering the compositions of planetesimals. Science 286, 1331-1335. 
601

602

603

604

605

606

607

608

609

610

611

612

613

614

615

616

617

618

619

620

621

622

623

624

625

626

627

628

629

630

631

632

633

634

635

Zolensky M.E., Bodnar R.J., Gibson E.K., Nyquist L.E., Reese Y., Shih C.-Y. and Wiesmann H. (1999) Asteroidal Water Within Fluid Inclusion-Bearing Halite in an H5 Chondrite, Monahans. Science 285, 1377-1379.

\section{Figure captions}

Figure 1: SEM images of 12 type I chondrules in Paris from the section with epoxy - Chondrules 1, 19 and 27: barred olivine. Chondrule 19 exhibits a well-preserved glassy mesostasis. Chondrule 4: radial pyroxene. Others chondrules are porphyritics. They presented various stages of aqueous alteration. Some of them like chondrule 6 or D exhibit well-preserved Fe grains, sign of low aqueous alteration. In the other hand, chondrule 27 has its mesostasis transformed into phyllosilicates and an aqueous alteration rim grew around him.

Figure 2: $\mathrm{OH}^{-} / \mathrm{Si}^{-}$vs $\mathrm{H}_{2} \mathrm{O} / \mathrm{SiO}_{2}$ (ppm/wt.\%) calibration for the quantification of water contents. Dashed lines are regression lines calculated with the $\mathrm{R}$ program.

Figure 3: Water content distribution in olivine and pyroxene chondrule minerals of Renazzo, Bishunpur and Paris chondrites. Y axis represents the cumulate number of analyses.

Figure 4: Distribution of $\delta$ D values in the olivines, pyroxenes and mesostases of Renazzo, Bishunpur and Paris chondrules.

Figure 5: NanoSIMS images of an area $\left(20 \times 20 \mu \mathrm{m}^{2}\right)$ of Paris chondrule A. (a) ${ }^{27} \mathrm{Al}^{16} \mathrm{O}^{-}$image permits to distinguish mesostasis (Mes) and olivine $(\mathrm{Ol})$. (b) $\mathrm{D}^{-} / \mathrm{H}^{-}$ratio image. We defined ROIs for each phase (blue lines) that fit in both images. The ROI is chosen smaller than the phases due to the different image resolution and the possible shifting occurring between the elemental images and the isotopic image.

Figure 6: Fractionation coefficients between olivine and mesostasis versus pyroxene and mesostasis reported in per mil. Black square symbols represent our analyses and gray square symbols stand for the distillation numerical simulation explained in section 4.2.3. Arrows indicate direction of fractionation for hydrous alteration of the Paris chondrules, which is unidirectional. The direction will depend on the alteration parameters.

\section{Table captions}

Table 1-EMPA analyses of olivines and pyroxenes from 6 Paris chondrules.

Table 2 - Chemical compositions of standards: (a) from Koga et al. (2003), (b) from Clog (2010), (c) from Deloule et al. (1991).

Table 3 - NanoSIMS data of water concentrations and hydrogen isotopic ratios (expressed in $\delta \mathrm{D})$ of mesostases, olivines and pyroxenes from 3 Renazzo chondrules (session IV), 4 Bishunpur chondrules (session IV) and 12 Paris chondrules (session III). For sessions II and III, the water concentrations are not 
636 reported in the table because the data were obtained at low primary beam intensity and background 637 correction could not be done. 


\begin{tabular}{|c|c|c|c|c|c|c|c|c|c|c|c|c|c|c|}
\hline (wt.\%) & MgO & $\mathrm{Al}_{2} \mathrm{O}_{3}$ & $\mathrm{SiO}_{2}$ & $\mathrm{~K}_{2} \mathrm{O}$ & $\mathrm{CaO}$ & $\mathrm{TiO}_{2}$ & $\mathrm{Cr}_{2} \mathrm{O}_{3}$ & MnO & $\mathrm{FeO}$ & $\mathrm{NiO}$ & Total & $\mathbf{F a}$ & Fs & Wo \\
\hline \multicolumn{15}{|l|}{ Chondrule 27} \\
\hline Olivine & 54 & 0 & 41.4 & 0 & 0.2 & 0.02 & 0.44 & 0.15 & 1.11 & 0.04 & 97.6 & 1.2 & & \\
\hline Olivine & 54.2 & 0 & 40.8 & 0 & 0.22 & 0.02 & 0.55 & 0.2 & 1.01 & 0.06 & 97.2 & 1.1 & & \\
\hline Pyroxene & 31.3 & 1.2 & 45.3 & 0.04 & 0.78 & 0.22 & 1.8 & 0.17 & 11.87 & 1.32 & 100.9 & & 17.5 & 0.4 \\
\hline Pyroxene & 34.2 & 0.8 & 51.9 & 0 & 0.8 & 0.27 & 0.61 & 0.2 & 2.53 & 0.08 & 91.9 & & 3.9 & 1.6 \\
\hline \multicolumn{15}{|l|}{ Chondrule 19} \\
\hline Olivine & 54.3 & 0.2 & 42.3 & 0 & 0.29 & 0.03 & 0.13 & 0.08 & 0.8 & 0.02 & 98.3 & 0.8 & & \\
\hline Pyroxene & 37.5 & 1.2 & 57 & 0 & 0.47 & 0.19 & 0.4 & 0.08 & 0.97 & 0.09 & 97.9 & & 1.4 & 0.9 \\
\hline Pyroxene & 47.9 & 0.5 & 46.8 & 0.01 & 0.24 & 0.1 & 0.37 & 0.14 & 1.56 & 0.03 & 97.9 & & 1.8 & 0.4 \\
\hline \multicolumn{15}{|l|}{ Chondrule 4} \\
\hline Pyroxene & 36.3 & 0.6 & 55.7 & 0.01 & 0.62 & 0.08 & 0.85 & 0.26 & 1.77 & 0 & 96.4 & & 2.6 & 1.2 \\
\hline Pyroxene & 33.8 & 0.7 & 53.4 & 0.02 & 0.71 & 0.11 & 1.59 & 0.27 & 5.33 & 0.32 & 97.3 & & 8.0 & 1.4 \\
\hline \multicolumn{15}{|l|}{ Chondrule 24} \\
\hline Olivine & 54.6 & 0.2 & 41.1 & 0.01 & 0.58 & 0.1 & 0.34 & 0.09 & 0.87 & 0 & 98 & 0.9 & & \\
\hline Olivine & 54.6 & 0.2 & 40.8 & 0 & 0.5 & 0.07 & 0.24 & 0 & 0.89 & 0 & 97.4 & 0.9 & & \\
\hline Pyroxene & 35.9 & 2.2 & 56.5 & 0.02 & 1.78 & 0.3 & 0.55 & 0 & 0.44 & 0 & 97.8 & & 0.7 & 3.4 \\
\hline Pyroxene & 34.1 & 2.9 & 56.6 & 0 & 2.99 & 0.3 & 0.56 & 0.07 & 0.63 & 0.02 & 98.2 & & 1.0 & 5.9 \\
\hline Pyroxene & 21.7 & 2 & 52.7 & 0 & 18.86 & 1.01 & 0.53 & 0.14 & 0.36 & 0.06 & 97.5 & & 0.6 & 38.3 \\
\hline \multicolumn{15}{|l|}{ Chondrule 6} \\
\hline Olivine & 52.1 & 0.1 & 40.6 & 0 & 0.47 & 0.05 & 0.43 & 0.17 & 1.38 & 0.05 & 95.8 & 1.5 & & \\
\hline Olivine & 54.6 & 0 & 41.2 & 0.02 & 0.19 & 0 & 0.53 & 0.13 & 1.46 & 0.12 & 98.3 & 1.5 & 3.6 & 1.0 \\
\hline Pyroxene & 37.6 & 1.3 & 56.8 & 0.02 & 0.54 & 0.27 & 0.4 & 0 & 0.88 & 0.05 & 98.1 & & 1.3 & 1.0 \\
\hline Pyroxene & 38.2 & 1.3 & 53.6 & 0 & 0.55 & 0.2 & 0.5 & 0.15 & 2.6 & 0.17 & 97.5 & & & \\
\hline \multicolumn{15}{|l|}{ Chondrule 9} \\
\hline Olivine & 54.4 & 0.1 & 40.9 & 0 & 0.31 & 0.11 & 0.46 & 0.14 & 1.2 & 0.03 & 97.8 & 1.2 & & \\
\hline Olivine & 54.5 & 0.1 & 41.2 & 0 & 0.31 & 0.01 & 0.48 & 0.12 & 1.61 & 0.07 & 98.4 & 1.6 & & \\
\hline Pyroxene & 32.5 & 2.1 & 50.7 & 0.03 & 0.97 & 0.25 & 0.81 & 0.25 & 6.84 & 0.04 & 95.3 & & 10.4 & 1.9 \\
\hline Pyroxene & 35.1 & 2 & 54.1 & 0.01 & 0.99 & 0.14 & 0.71 & 0.11 & 3.2 & 0.01 & 96.6 & & 4.8 & 1.9 \\
\hline Pyroxene & 30 & 0.5 & 47.7 & 0.01 & 1.2 & 0.13 & 1.61 & 0.37 & 4.13 & 0.04 & 85.9 & & 7.0 & 2.6 \\
\hline
\end{tabular}

640 Table 1 
641

\begin{tabular}{|c|c|c|c|c|c|c|c|c|c|c|c|c|c|c|c|}
\hline & $\begin{array}{l}\mathrm{H}_{2} \mathrm{O} \\
(\mathrm{ppm})\end{array}$ & $\begin{array}{c}\delta D \\
(\%)\end{array}$ & $\begin{array}{c}\mathrm{SiO}_{2} \\
(\mathrm{wt} . \%)\end{array}$ & $\begin{array}{l}\mathrm{Al}_{2} \mathrm{O}_{3} \\
\text { (wt.\%) }\end{array}$ & $\begin{array}{c}\mathrm{FeO} \\
\text { (wt.\%) }\end{array}$ & $\begin{array}{c}\mathrm{MnO} \\
\text { (wt.\%) }\end{array}$ & $\begin{array}{l}\mathrm{MgO} \\
\text { (wt.\%) }\end{array}$ & $\begin{array}{c}\mathrm{CaO} \\
\text { (wt.\%) }\end{array}$ & $\begin{array}{l}\mathrm{Na}_{2} \mathrm{O} \\
\text { (wt.\%) }\end{array}$ & $\begin{array}{c}\mathrm{K}_{2} \mathrm{O} \\
\text { (wt.\%) }\end{array}$ & $\begin{array}{l}\mathrm{Cr}_{2} \mathrm{O}_{3} \\
\text { (wt.\%) }\end{array}$ & $\begin{array}{c}\mathrm{TiO}_{2} \\
\text { (wt.\%) }\end{array}$ & $\begin{array}{l}\mathrm{P}_{2} \mathrm{O}_{5} \\
\text { (wt.\%) }\end{array}$ & $\begin{array}{c}\mathrm{Cl} \\
\text { (wt.\%) }\end{array}$ & $\begin{array}{l}\text { Total } \\
(\%)\end{array}$ \\
\hline \multicolumn{16}{|l|}{ Olivine $^{\text {(a) }}$} \\
\hline KLV-23 & 120 & - & 40.32 & 0.05 & 12.27 & - & 47.47 & 0.08 & 0,03 & - & - & 0.03 & - & - & 100.26 \\
\hline \multicolumn{16}{|c|}{ Pyroxene $^{(\mathrm{a})}$} \\
\hline KBH-1 & 186 & - & 54.68 & 4.73 & 5.88 & - & 32.92 & 0.86 & 0.12 & - & - & 0.11 & - & - & 99.32 \\
\hline \multicolumn{16}{|l|}{ Glasses $^{(b)}$} \\
\hline DR15-2-5 & 2581 & -74 & 50.81 & 14.78 & 11.15 & 0.20 & 6.95 & 10.37 & 3.10 & 0.46 & - & 1.82 & 0.21 & 0.02 & 99.85 \\
\hline DR20-1-1 & 3988 & -61 & 50.20 & 15.13 & 10.95 & 0.20 & 6.89 & 10.82 & 3.07 & 0.28 & - & 1.92 & 0.28 & 0.03 & 99.74 \\
\hline \multicolumn{16}{|c|}{ Amphiboles (c) } \\
\hline Mt Emma & 14300 & -50 & 40.87 & 13.96 & 9.84 & 0.08 & 14.32 & 10.79 & 2.56 & 1.55 & 0.09 & 2.89 & - & 0.04 & 98.51 \\
\hline Kipawa & 14500 & -88 & 45.05 & 8.32 & 12.77 & 0.24 & 14.01 & 10.90 & 2.48 & 1.05 & 0.05 & 0.80 & - & 0.59 & 98.49 \\
\hline
\end{tabular}

643 Table 2

644

645

646

647

648

649

650

651

652

653

654 


\begin{tabular}{|c|c|c|c|}
\hline Chondre & Phase & $\begin{array}{c}\delta D \\
(\%)\end{array}$ & $\begin{array}{c}\mathrm{H}_{2} \mathrm{O} \\
(\mathrm{ppm})\end{array}$ \\
\hline \multicolumn{4}{|l|}{ Renazzo } \\
\hline \multicolumn{4}{|l|}{ Session IV } \\
\hline \multirow[t]{5}{*}{ Chondrule $X$} & mesostasis & $-73 \pm 146$ & - \\
\hline & mesostasis & $-81 \pm 150$ & $2284 \pm 275$ \\
\hline & olivine & $-139 \pm 132$ & $115 \pm 58$ \\
\hline & mesostasis & $15 \pm 156$ & - \\
\hline & pyroxene & $-116 \pm 137$ & $366 \pm 183$ \\
\hline \multirow[t]{6}{*}{ Chondrule $Y$} & olivine & $-188 \pm 129$ & $182 \pm 91$ \\
\hline & olivine & $-115 \pm 150$ & $196 \pm 98$ \\
\hline & mesostasis & $-212 \pm 125$ & - \\
\hline & mesostasis & $-211 \pm 121$ & $32373 \pm 3899$ \\
\hline & pyroxene & $-109 \pm 142$ & $1481 \pm 740$ \\
\hline & pyroxene & $-120 \pm 140$ & $1407 \pm 703$ \\
\hline \multirow[t]{6}{*}{ Chondrule Z } & olivine & $-192 \pm 126$ & $158 \pm 79$ \\
\hline & pyroxene & $-161 \pm 132$ & $320 \pm 160$ \\
\hline & olivine & $-120 \pm 128$ & $133 \pm 67$ \\
\hline & olivine & $-125 \pm 137$ & $215 \pm 108$ \\
\hline & olivine & $-148 \pm 132$ & $94 \pm 47$ \\
\hline & surrounding matrix & $316 \pm 202$ & - \\
\hline
\end{tabular}

\section{Bishunpur}

\section{Session IV}

Chondrule I

mesostasis

olivine

olivine

mesostasis

olivine

olivine

pyroxene

pyroxene

surrounding matrix

Chondrule J pyroxene

pyroxene

pyroxene

pyroxene

olivine

pyroxene

surrounding matrix
$-166 \pm 133$

$-30 \pm 151$

$-164 \pm 137$

$-53 \pm 146$

$-149 \pm 135$

$0 \pm 156$

$52 \pm 163$

$137 \pm 176$

$-113 \pm 136$

$$
\begin{array}{r}
-60 \pm 145 \\
-118 \pm 138 \\
-149 \pm 131 \\
-81 \pm 143 \\
-115 \pm 136 \\
-95 \pm 152 \\
-119 \pm 136
\end{array}
$$

$4702 \pm 566$

$121 \pm 61$

$159 \pm 79$

$4725 \pm 569$

$399 \pm 199$

$159 \pm 79$

$659 \pm 330$

$1244 \pm 622$

$1328 \pm 664$

$1796 \pm 898$

$1395 \pm 698$

$674 \pm 337$

$76 \pm 38$

$649 \pm 324$ 
pyroxene

mesostasis

Chondrule L mesostasis

pyroxene

mesostasis

pyroxene

olivine

olivine

pyroxene

pyroxene
$-18 \pm 153$

$-46 \pm 148$

$-122 \pm 138$

$-44 \pm 149$

$-49 \pm 148$

$20 \pm 159$

$5641 \pm 679$

$1090 \pm 545$

$15107 \pm 1819$

$567 \pm 284$

$316 \pm 158$

$326 \pm 163$

$266 \pm 131$

656

657

\begin{tabular}{|c|c|c|c|}
\hline Chondre & Phase & $\begin{array}{c}\delta D \\
(\% \circ)\end{array}$ & $\begin{array}{c}\mathrm{H}_{2} \mathrm{O} \\
\text { (ppm) }\end{array}$ \\
\hline \multicolumn{4}{|l|}{ Session I } \\
\hline \multirow{7}{*}{ Chondrule 4} & mesostasis & $-129 \pm 31$ & \\
\hline & pyroxene & $-121 \pm 61$ & \\
\hline & mesostasis & $-90 \pm 31$ & \\
\hline & pyroxene & $-86 \pm 31$ & - \\
\hline & mesostasis & $-104 \pm 32$ & - \\
\hline & pyroxene & $-89 \pm 35$ & - \\
\hline & surrounding matrix & $-94 \pm 100$ & - \\
\hline \multirow[t]{6}{*}{ Chondrule24 } & mesostasis & & - \\
\hline & pyroxene & $-80 \pm 43$ & - \\
\hline & olivine & $19 \pm 54$ & - \\
\hline & mesostasis & $-252 \pm 38$ & - \\
\hline & olivine & $-125 \pm 50$ & - \\
\hline & pyroxene & $-12 \pm 44$ & - \\
\hline \multirow[t]{5}{*}{ Chondrule 6} & mesostasis & $-97 \pm 30$ & - \\
\hline & olivine & $-130 \pm 35$ & - \\
\hline & olivine & $18 \pm 45$ & - \\
\hline & pyroxene & $-34 \pm 35$ & - \\
\hline & surrounding matrix & $-27 \pm 39$ & - \\
\hline \multirow[t]{4}{*}{ Chondrule19 } & mesostasis & $-23 \pm 45$ & - \\
\hline & olivine & $-21 \pm 38$ & - \\
\hline & olivine & $0 \pm 46$ & - \\
\hline & pyroxene & $-91 \pm 37$ & - \\
\hline \multirow[t]{2}{*}{ Chondrule27 } & mesostasis & $-182 \pm 28$ & - \\
\hline & olivine & $-24 \pm 43$ & - \\
\hline
\end{tabular}




\begin{tabular}{|c|c|c|c|}
\hline & mesostasis & $-212 \pm 27$ & - \\
\hline & pyroxene & $20 \pm 27$ & - \\
\hline \multirow[t]{6}{*}{ Chondrule 9} & pyroxene & $-41 \pm 36$ & - \\
\hline & mesostasis & $64 \pm 40$ & - \\
\hline & pyroxene & $22 \pm 41$ & - \\
\hline & pyroxene & $155 \pm 53$ & - \\
\hline & surrounding matrix & $-77 \pm 75$ & \\
\hline & & & - \\
\hline \multicolumn{4}{|l|}{ Paris } \\
\hline \multicolumn{4}{|l|}{ Session II } \\
\hline \multirow[t]{8}{*}{ Chondrule 1} & olivine & $-93 \pm 28$ & - \\
\hline & mesostasis & $140 \pm 36$ & - \\
\hline & mesostasis & $115 \pm 36$ & - \\
\hline & olivine & $-66 \pm 48$ & - \\
\hline & pyroxene & $-62 \pm 32$ & - \\
\hline & mesostasis & $37 \pm 30$ & - \\
\hline & olivine & $-213 \pm 31$ & - \\
\hline & pyroxene & $21 \pm 45$ & \\
\hline \multirow[t]{5}{*}{ Chondrule 7} & mesostasis & $-96 \pm 26$ & - \\
\hline & olivine & $-116 \pm 30$ & - \\
\hline & mesostasis & $-132 \pm 24$ & - \\
\hline & olivine & $-36 \pm 30$ & - \\
\hline & pyroxene & $-113 \pm 50$ & - \\
\hline \multirow{2}{*}{\multicolumn{4}{|c|}{$\begin{array}{l}\text { Paris } \\
\text { Session II }\end{array}$}} \\
\hline \multicolumn{3}{|c|}{ Session III } & \\
\hline \multirow[t]{12}{*}{ Chondrule A } & olivine & $-374 \pm 30$ & $603 \pm 145$ \\
\hline & olivine & $-279 \pm 29$ & $758 \pm 182$ \\
\hline & olivine & $-334 \pm 31$ & $961 \pm 231$ \\
\hline & olivine & $-179 \pm 45$ & $949 \pm 228$ \\
\hline & mesostasis & $-17 \pm 25$ & $30720 \pm 1516$ \\
\hline & mesostasis & $-274 \pm 18$ & $6175 \pm 305$ \\
\hline & olivine & $-398 \pm 23$ & $961 \pm 231$ \\
\hline & mesostasis & $266 \pm 119$ & $6470 \pm 319$ \\
\hline & olivine & $76 \pm 36$ & $781 \pm 188$ \\
\hline & pyroxene & $-179 \pm 25$ & $503 \pm 121$ \\
\hline & pyroxene & $-342 \pm 23$ & $985 \pm 237$ \\
\hline & mesostasis & $-175 \pm 22$ & $5630 \pm 278$ \\
\hline \multirow[t]{5}{*}{ Chondrule B } & mesostasis & & $66419 \pm 3277$ \\
\hline & pyroxene & & $860 \pm 207$ \\
\hline & olivine & & $844 \pm 203$ \\
\hline & pyroxene & & $900 \pm 216$ \\
\hline & olivine & & $859 \pm 206$ \\
\hline
\end{tabular}


olivine

mesostasis

pyroxene

pyroxene

Chondrule D mesostasis

olivine

mesostasis

pyroxene

Chondrule $\mathrm{E}$ mesostasis

pyroxene

olivine

mesostasis

olivine

mesostasis

olivine

mesostasis

olivine

olivine
$998 \pm 240$

$101 \pm 34$

$-225 \pm 21$

$-172 \pm 22$

$-102 \pm 29$

$-225 \pm 21$

$-270 \pm 21$

$-337 \pm 20$

$191 \pm 29$

$83 \pm 27$

$-172 \pm 31$

$112 \pm 29$

$13 \pm 29$

$366 \pm 35$

$-138 \pm 27$

$-292 \pm 32$

$-208 \pm 23$

$-225 \pm 29$
$33462 \pm 1651$

$698 \pm 168$

$1174 \pm 282$

$8931 \pm 441$

$799 \pm 182$

$7940 \pm 392$

$595 \pm 143$

$87466 \pm 4317$

$615 \pm 148$

$10934 \pm 539$

$1051 \pm 253$

$31575 \pm 1558$

$933 \pm 224$

$15926 \pm 786$

$905 \pm 218$

$639 \pm 154$

658

659 Table 3

660 

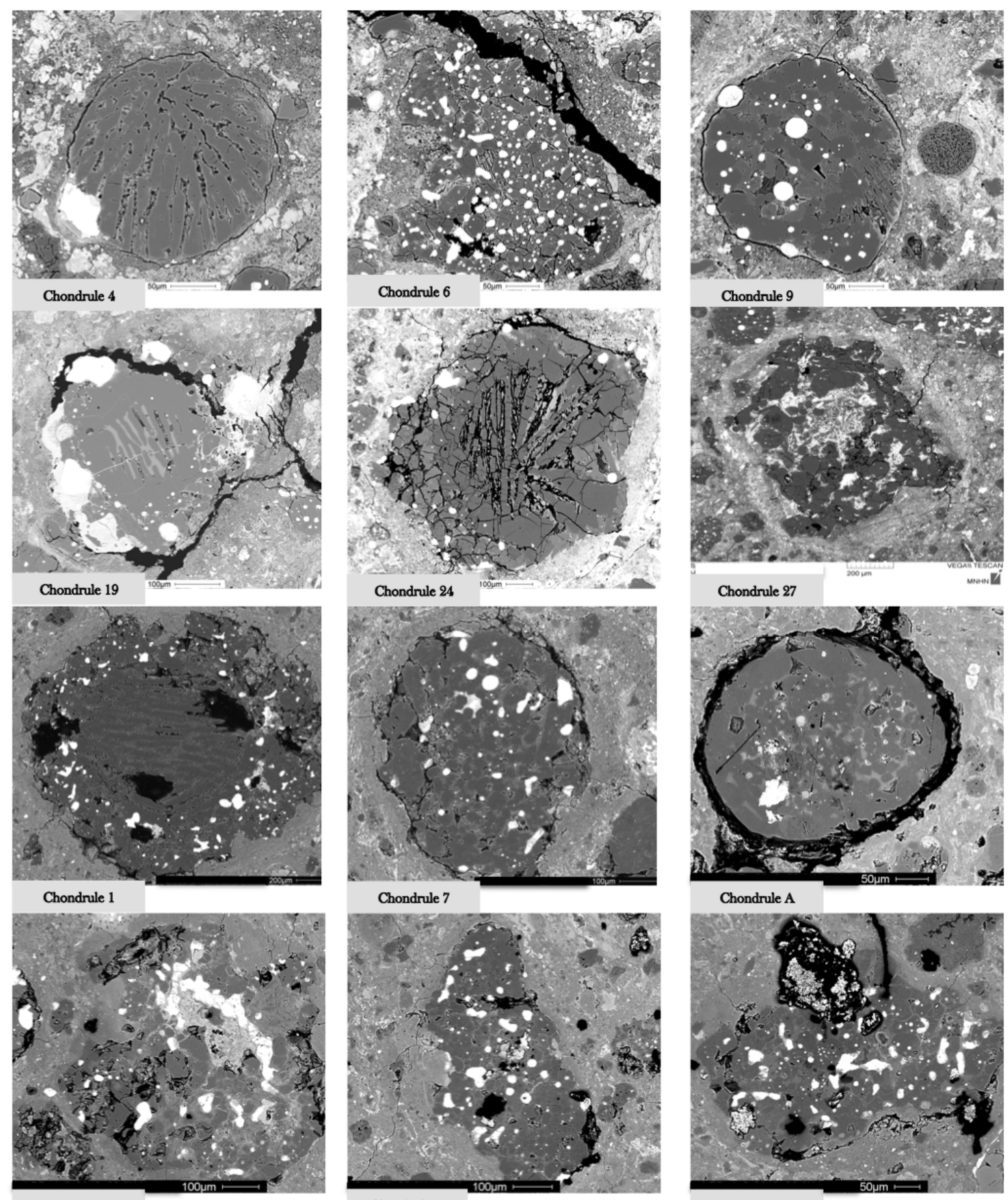

Chondrule B

Chondrule D

Chondrule E 


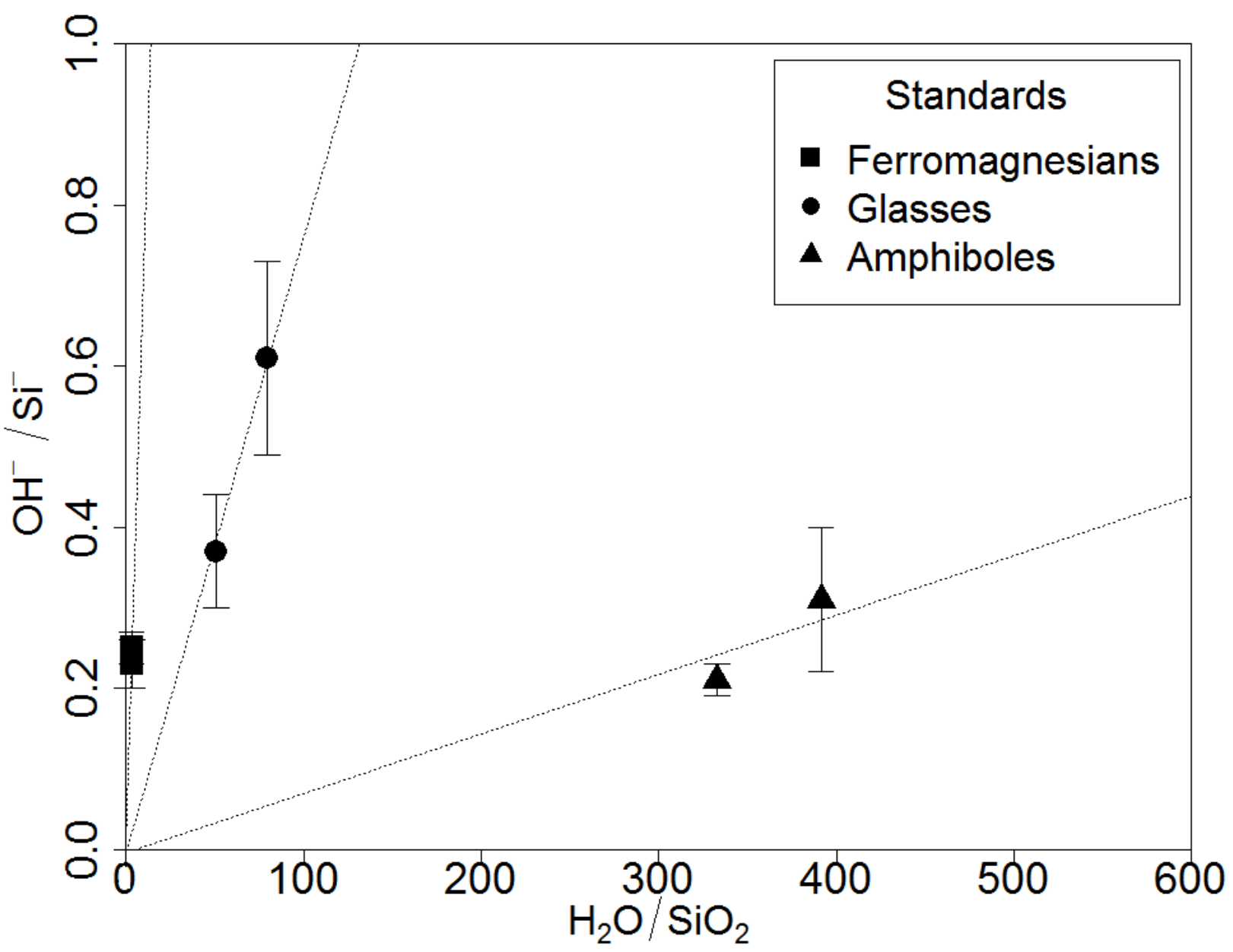

663

664 

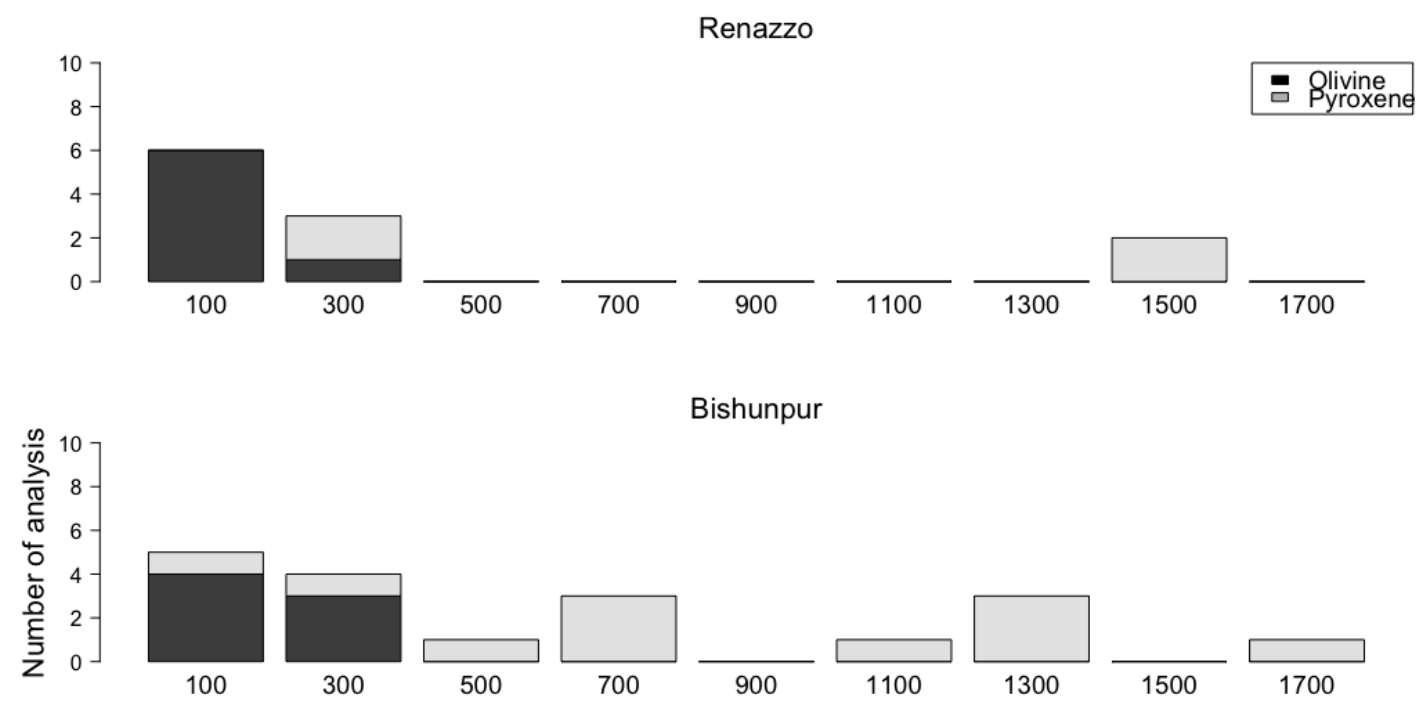

665

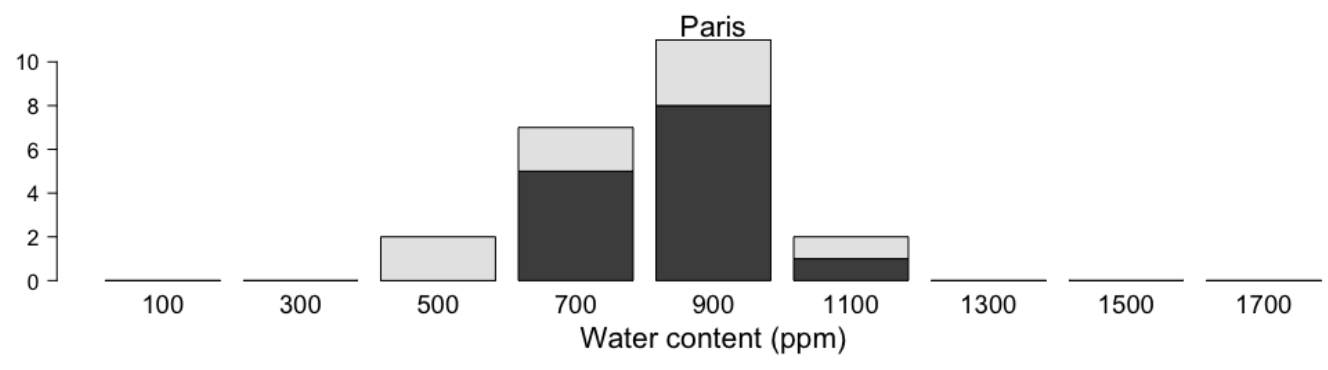



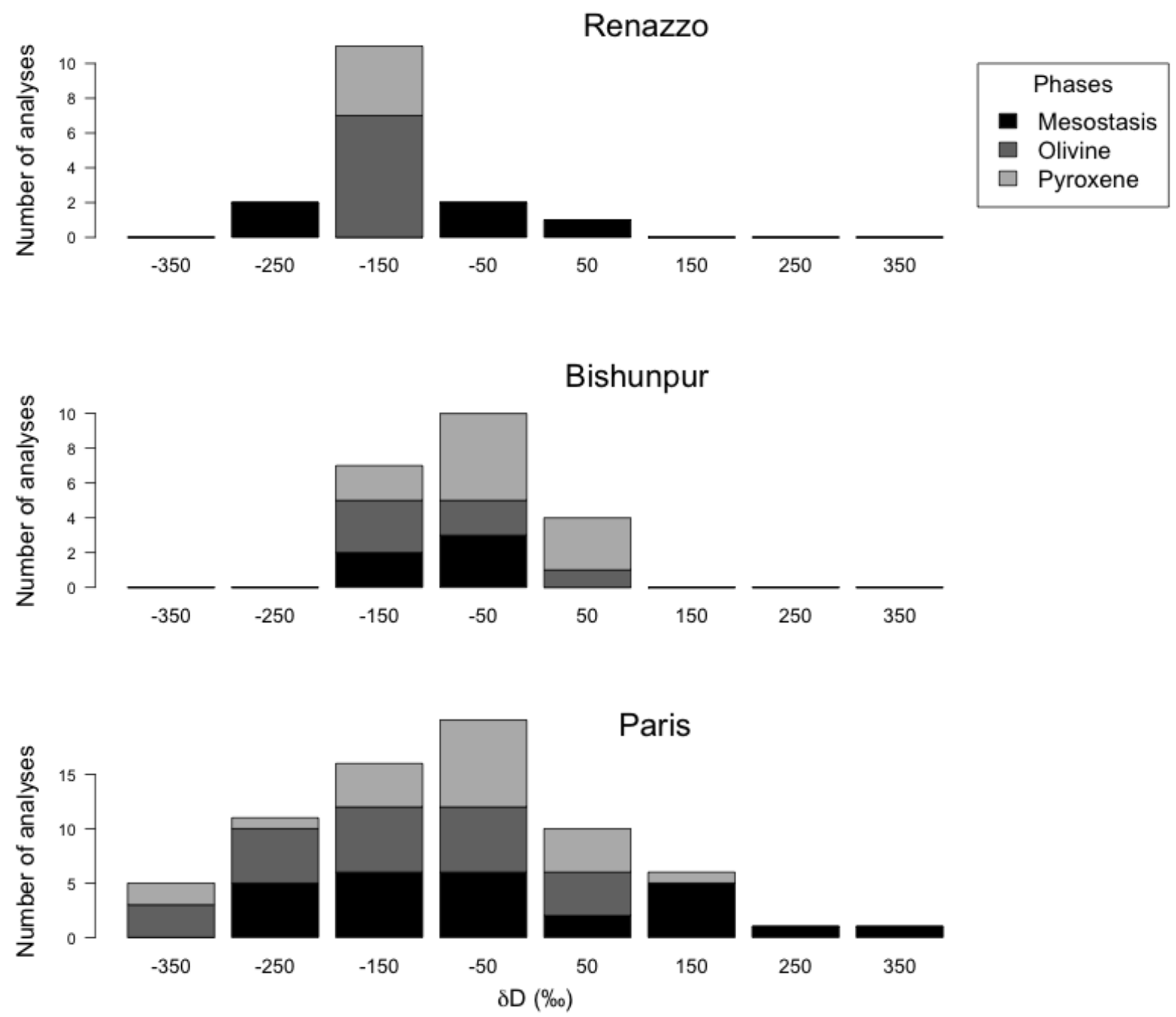

667

668 
669

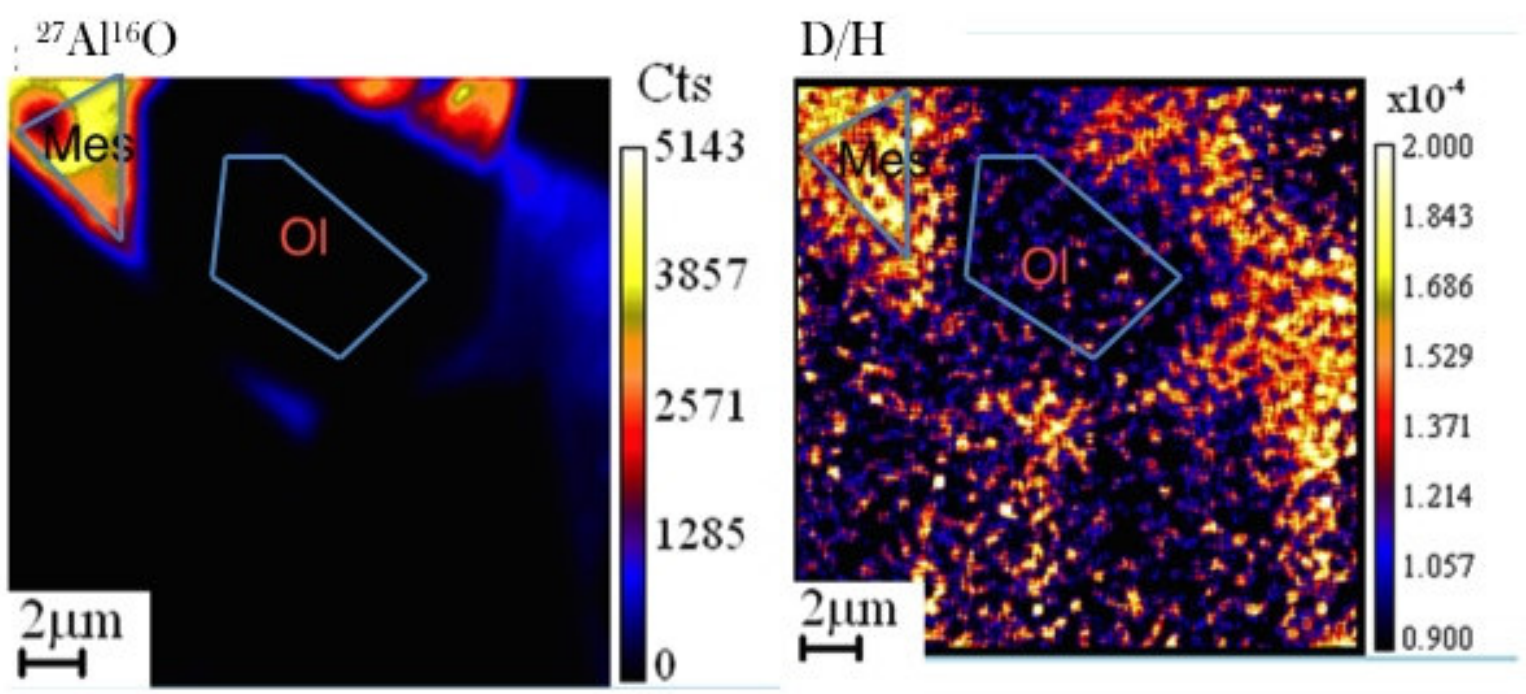

670 


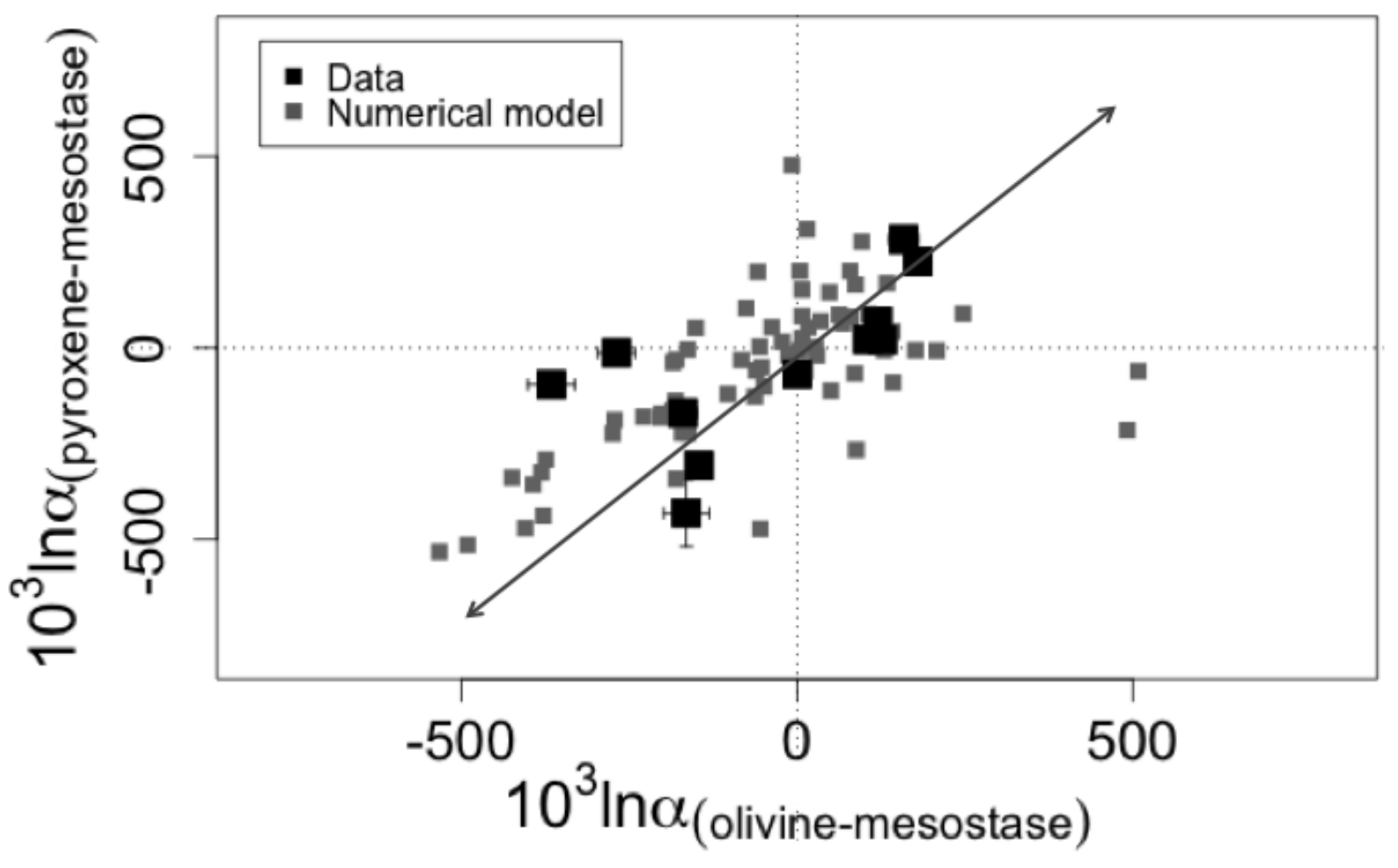

671 